\title{
Improving the management of STIs among MCH/FP clients at the Nakuru Municipal Council health clinics
}

Julie Solo

Baker Ndugga Maggwa

James Kariba Wabaru

Bedan Kiare Kariuki

Gregory Maitha

Follow this and additional works at: https://knowledgecommons.popcouncil.org/departments_sbsr-rh

Part of the Demography, Population, and Ecology Commons, Family, Life Course, and Society Commons, International Public Health Commons, and the Women's Health Commons How does access to this work benefit you? Let us know!

\section{Recommended Citation}

Solo, Julie, Baker Ndugga Maggwa, James Kariba Wabaru, Bedan Kiare Kariuki, and Gregory Maitha. 1999. "Improving the management of STIs among MCH/FP clients at the Nakuru Municipal Council health clinics," Africa OR/TA Project II. Nairobi: Population Council. 


\title{
Improving the \\ Management of STIS among $M C H / F P$ \\ clients at the Nakuru \\ Municipal Council \\ Health Clinics
}

\author{
Julie Solo \\ Ndugga Maggwa \\ Population Council \\ James Kariba Wabaru \\ Nakuru Municipal Council \\ Dr Bedan Kiare Kariuki \\ Provincial General Hospital, Nakuru \\ Gregory Maitha \\ Department of Medical Microbiology \\ University of Nairobi
}




\section{The Population Council}

The Population Council seeks to help improve the well-being and reproductive health of current and future generations around the world and to help achieve a humane, equitable, and sustainable balance between people and resources. The Council analyzes population issues and trends; conducts biomedical research to develop new contraceptives; works with public and private agencies to improve the quality and outreach of family planning and reproductive health services; helps governments to influence demographic behavior; communicates the results of research in the population field to appropriate audiences; and helps build research capacities in developing countries. The Council, a nonprofit, nongovernmental research organization established in 1952, has a multinational Board of Trustees; its New York headquarters supports a global network of regional and country offices.

\section{Africa OR/TA Project II}

The overall objectives of the Africa OR/TA Project 11 are to broaden understanding of how to improve family planning services in Sub-Saharan Africa, and to apply operations research and technical assistance to improve services by:

- Increasing access to a full range of family planning services and methods;

- Developing service delivery strategies that are client-oriented and acceptable to various population groups;

- Improve the operations of programs to make them more efficient and financially sustainable;

- Improving the quality of services;

- Strengthening the capabilities of family planning program managers to use operations research to diagnose and solve delivery problems.

This study was supported by the Population Council's Africa Operations Research and Technical Assistance Project II, Project No. 936-3030, funded by USAID contract No. CCP-C-00-3008-00 of the Office of Population, and by the Population Council's Cooperative Agreement No. CCP-3050-00 funded by USAID Bureau of Africa, Office of Sustainable Development. 


\section{TABLE OF CONTENTS}

PAGE

Executive Summary

$\begin{array}{ll}\text { Introduction } & 1\end{array}$

Study Design and Data Collection 6

Methodology and Objectives 6

Field Work and Data Collection 8

$\begin{array}{ll}\text { Laboratory Procedures } & 10\end{array}$

Data Entry and Analysis $\quad 11$

$\begin{array}{ll}\text { Findings } & 13\end{array}$

Characteristics of Sample $\quad 13$

$\begin{array}{ll}\text { Symptoms } & 17\end{array}$

$\begin{array}{ll}\text { Clinical Signs } & 18\end{array}$

Risk Factor Information $\quad 19$

Effectiveness of Syndromic Management 21

$\begin{array}{ll}\text { Provider and client perspectives } & 29\end{array}$

Concluding Observations and Recommendations 34

Reference and Notes

Appendix 


\section{ACKNOWLEGEMENTS}

This study was undertaken with substantial support from many people whose assistance is gratefully acknowledged. At the Nakuru Municipal Council, special thanks go to the Medical Officer of Health, the clinic staff and the clients who agreed to participate in the study and for all the support they gave to the study team. Special thanks also go to Mr. Francis Ayuka who ably coordinated the field activities for the project and the team of researchers who assisted with the data collection. Special mention must be made of Prof. J.J. Bwayo the Chairman of the Department of Microbiology at the University of Nairobi for having made his laboratories facilities and staff available to support this study and Mr. I. Onyango who worked tirelessly to ensure that laboratory tests were carried out and the results reached the study clinics in good time. At the Population Council offices, special thanks go to Ms. Monica Wanjiru- the Communications Specialist, Ms. Violet Bukusi and Ms. Joanne Lewa- FRONTIERS Project assistants for typesetting and editing the report. 


\section{ABBREVIATIONS}

ANC

FP

HIV

AIDS

$\mathrm{MCH}$

STI

RTI

PPV

PV

LCR

IEC

WHO

UNAIDS

ICPD

PID

REDSO/ESA

USAID

HVS

HDS

$\mathrm{MOH}$
Antenatal Care

Family Planning

Human Immune Deficiency Virus

Acquired Immune Deficiency Syndrome

Maternal Child Health

Sexually Transmitted Infection

Reproductive Tract Infection

Positive Predictive Value

Predictive Value

Ligase Chain Reaction

Information, Educaitonand Counselling

World Health Organization

Joint United Nations Program on AIDS

Interaction Conference on Population and Development

Pelvic Inflammatory Desease

Regional Economic Development Services Office for East and Southern Africa

United States Agency for International Development

High Visual Swal

Demographic and Health Survery

Ministry of Health 


\section{EXECUTIVE SUMMARY}

\section{Introduction}

In an effort to address the global crisis of HIV/ AIDS and to reducethe spread of other sexually transmitted infections (STIS), maternal and child health/ family planning programs have attempted to integrate the management of STIs into their services. This integration was endorsed at the 1994 International Conference on Population and Development in Cairo. However, programs have encountered a number of difficulties as they try to effectively manage STIs in an $\mathrm{MCH}$ / FP setting. In particular, the effective detection and treatment of STIs has proved very difficult among $\mathrm{MCH} / \mathrm{FP}$ populations.

\section{Study Design}

This current study was developed to help improve integration efforts and to contribute to a reduction in the preval ence and spread of STIs among women receiving FP/ $\mathrm{MCH}$ services from the Nakuru Municipal Council health clinics in Kenya. The project specifically looked at the validity of the current syndromic management approach and explored various ways to improve its approach through the incorporation of risk assessment. This was done through collecting three types of information from all new antenatal (ANC) and both new and revisit family planning (FP) clients who were recruited into the study.

- findings from the medical examination including symptoms and clinical signs;

- risk factor information obtained by providers through the use of a checklist;

- laboratory results from specimens collected during the examination. Laboratory tests were conducted for five reproductive tract infections (RTIS): gonorrhea, chlamydia, trichomoniasis, bacterial vaginosis and candidiasis.

\section{Summary of Key Findings}

Characteristics of ANC and FP clients

-A total of 906 family planning clients and 815 antenatal clients were approached and consented to participate in the study

-A ntenatal clients were younger, more likely to be single and had fewer living children compared with the family planning clients 
- $\quad$ RTIs are very common in this population, with 59 and 50 percent of ANC and FP clients, respectively, having at least one infection.

- $\quad$ Multiple infections were common among both family planning and antenatal clients. A mong clients who had laboratory evidence of any RTI, $23.5 \%$ and $39.4 \%$ of family planning and antenatal clients, respectively, had multiple infections.

- $\quad$ The majority of women with an RTI are asymptomatic; only $29 \%$ and $23 \%$ of ANC and FP clients, respectively, with an infection had at least one symptom.

- A large proportion of infections is not sexually transmitted. Sexually transmitted infections were present in $29.8 \%$ family planning and $36.4 \%$ antenatal clients with laboratory evidence of an RTI compared with $84.4 \%$ and $85.1 \%$ who had non sexually transmitted infection, respectively

- Bacterial vaginosis considered to be a non-sexually transmitted infec tion has been found to be associated with pelvic inflammatory disease and increased risk for HIV infection. This infection was found in $28.0 \%$ and $26.6 \%$ of family planning and antenatal clients, respectively, in this study.

- $\quad$ Signs suggestive of RTIs were found in a larger proportion of clients (40\% A N C and $37 \%$ family planning). However, a significant proportion of women who reported abnormal vaginal discharge symptoms did not have clinical evidence of such a discharge. These data suggest a discrepancy between reported symptoms and clinical observations.

- $\quad$ Reported symptoms in partners are uncommon; only five percent of both ANC and FP clients answered yes to the presence of at least one of the nine symptoms asked about in their partners.

- $\quad$ Risk factors for STIs and HIV/AIDS are not common among women attending M CH/FP clinics. Also the vast majority of these women do not consider themselves at increased risk of getting STIs. Only $17.1 \%$ and $9.2 \%$ of family planning and antenatal clients considered themselves at increased risk of getting infected with an STI.

\section{Effectiveness of syndromic management}

- Although a significant proportion of women reported symptoms and/ or had signs suggestive of RTIs, few w ere diagnosed and treated through syndromic management. Of the women recruited into the study, only 14.8 and $4.6 \%$ of ANC and FP clients, respectively, were diagnosed to have any STI syndrome compared with $40 \%$ and $37 \%$ who had at least one sign suggestive of an infection. 
- The vaginal discharge syndrome only identifies a small proportion of the women with RTIs in this population; the sensitivity for vaginitis was only 16 and five percent for ANC and FP clients, respectively, while it was only 10 percent for ANC clients and six percent for FP clients for cervicitis.

- The vaginal discharge syndrome performs better when used to manage vaginal infections compared with cervical infections. Figure 1 below shows the positive predictive value (PPV) of vaginal discharge for cervicitis and vaginitis-that is, of the women diagnosed with vaginal discharge, what proportion actually had an infection. As this shows, it performs badly for cervicitis, but is better for vaginitis; roughly twothirds of clients diagnosed with vaginal discharge did have vaginitis.

Figure 1: Effectiveness of vaginal discharge syndrome in predicting reproductive tract infection

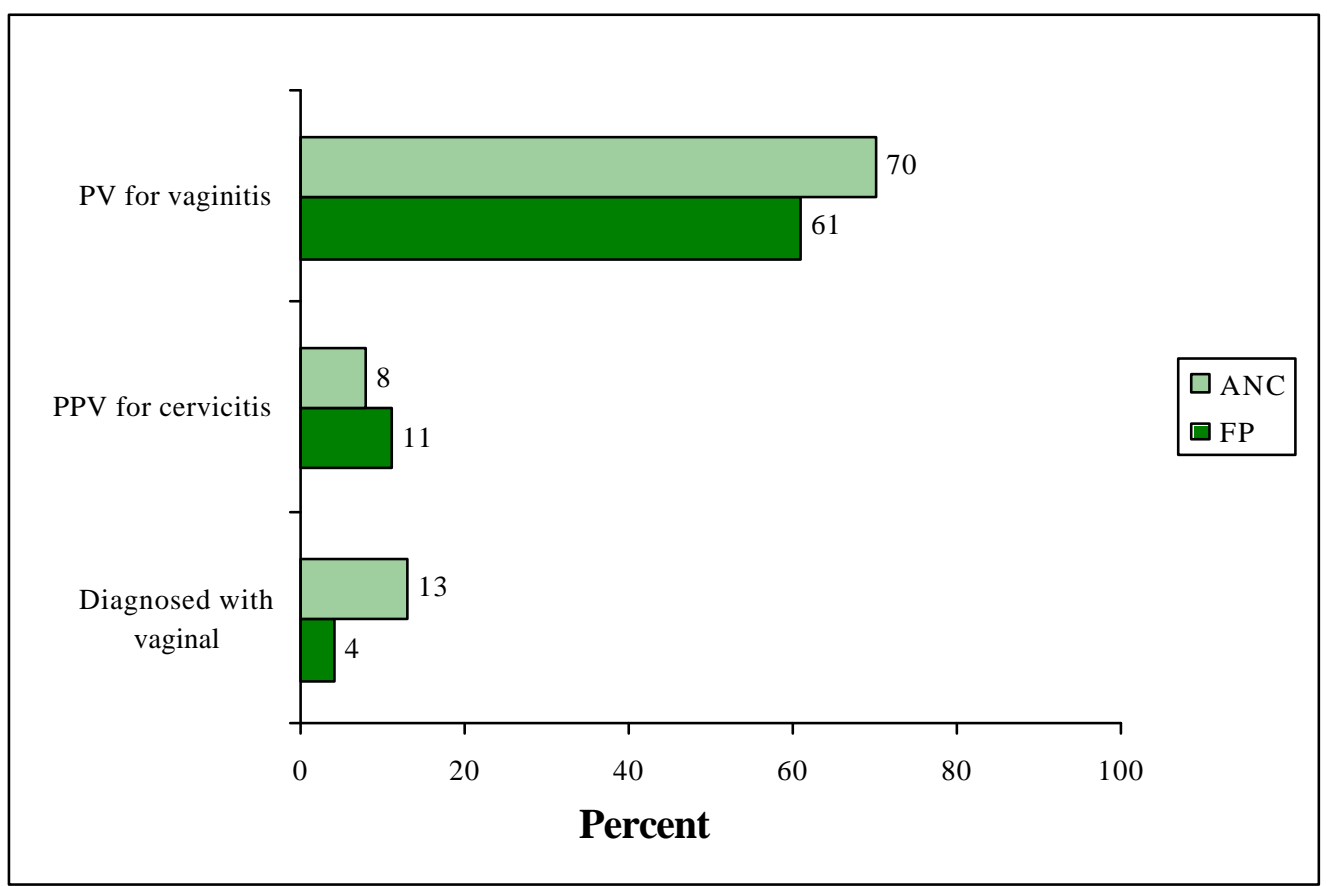

- $\quad$ Adding risk assessment information to the current symptom-based algorithms does not significantly improve on their ability to identify and manage cervicitis. Using logistic regression, thebest models fitted from the risk assessment information had poor sensitivity $5 \%$ and $7 \%$ for family planning and antenatal clients, respectively. However, the models had better specificity and positive predictive values compared with algorithms that depended only on clinical information.

- A significant proportion of clients did not return for their test result or scheduled follow-up visit. For example, of the clients for whom a syndromic diagnosis was made, $57 \%$ and $51 \%$ of family planning and antenatal clients, respectively, returned for their follow-up appointments. Therefore it was difficult to assess the effectiveness of syndromic approach in achieving clinical cure in clients for whom a syndromic diagnosis was made and treatment started. 
- $\quad$ Providers found the checklist to be a useful tool to use with clients. Although initially it was somewhat difficult, with time, most providers found it relatively easy to implement. The checklist enabled them to spend more time with the clients, collect more detailed information and to provide counseling to clients in a systematic manner.

- Providers were generally comfortable with clinical procedures, though some were only partly comfortable with pelvic exams since they had not been typically performing them.

- Clients werehappy to bereceiving thorough examinations, mostly because they wanted to know their health status: as one client said, "this is a blessing because of these exams. So many women will benefit and this should continue."

- Both clients and providers were generally comfortable with the risk assessment questions; in the words of one client, "the questions asked are good-they make one think."

\section{Recommendations}

Most of the findings for this study support the guidelines put forth in a recent document from USAID, Integration of Family Planning/M CH with HIV/STD Prevention, Programmatic Technical Guidance: Priority of Primary Prevention with a Focus on High Transmitters (December 1998). The document summarizes a number of weaknesses of integrated programs, including an overemphasis on the clinical management of STDs, the ineffectiveness of the syndromic algorithm for vaginal discharge, and inadequate support for primary prevention of sexual transmission of HIV and other STDs, especially for condom promotion and behavior change intervention.

can focus on $I \mathcal{E C}$,

condom promotion,

counse ling and

raising aware ness

about $\mathcal{S}$ TIs."

- $\quad$ Focus on prevention: given the problems associated with using the syndromic approach to identify and manage RTIs among women attending $\mathrm{MCH} / \mathrm{FP}$ clinics identified in this study, we should emphasize taking a public heal th approach where we emphasize

preventive approaches that have been shown to be cost-effective compared with treatment.

- Improve on STI/HIV IEC: the large discrepancy between reported symptoms and signs found during clinical examination might be a reflection of poor clients' knowledge of the symptoms associated with these infections. Therefore there is a need to improve skills of providers and to encourage them to undertake systemic STI/ HIV IEC for clients in order to improve on clients' knowledge of STI/ HIV related symptoms and signs. 
- Emphasis on clinical examinations: Data from the study showed major discrepancies between reported symptoms suggestive of RTIs and clinical findings. Clinical examinations identified more women with RTI related signs compared with reported symptoms. In addition, clinic staff were comfortable conducting the examinations and the clients appreciated being examined. Therefore, staff need to be encouraged and enabled to undertake clinical examinations for antenatal and family planning clients routinely.

- Encourage the use of integrated and standardized checklists in the provision of family planning, antenatal care and STI/HIV services. Data from the study showed that the checklist enabled more clients with symptoms and signs suggestive of STIs to be identified and the vast majority of clients received STI/ HIV counseling.

- Review our partner notification strategies and improve community understanding that not all infections are sexually transmitted given that most of the infections among w omen attending M CH/FP clinics are not sexually transmitted; as one provider explained, "we need to have a language to explain the infection... most RTIs are not STIs. The moment we label it an STI, we break up the family rather than unite the family."

- Review treatment guidel ines to emphasize effective treatment of vaginal infections, which have a high prevalence among this population; though there has been a strong focus on cervical infections, recent evidence indicates the importance of treating bacterial vaginosis and trichomoniasis both of which are much more common than gonorrhea and/ or chlamydia and have a high potential for serious health impacts.

- Continue using syndromic management in Nakuru to manage clients presenting with symptoms in spite of its problems, until there is something better; the following comments reflect this opinion from participants in Nakuru: "What alternative is there?"; "For some time we may have to do without labs as there are no funds to support them"; " meanwhile, we need to do something for those clients with symptoms." 
The Joint United Nations Program on HIV/ AIDS (UNAIDS) and the World Health Organization (WHO) estimate that the number of people living with HIV has grown to 33.4 million at the end of 1998, while almost 14 million people have al ready died from HIV. ${ }^{1}$ In 1995, the WHO estimated that there were 333 million cases of sexually transmitted infections (STIs), or roughly one million infections occurring every day, ${ }^{2}$ making STIs one of the most common causes of illness in the world. Sub-Saharan Africa is particularly affected by both of these problems. It is estimated that over two-thirds of the peoplenow living with HIV in theworld livein sub-Saharan Africa, 83 percent of theworld's AIDS deaths have been in this region, and this region accounts for 65 of the 333 million global STI cases (20 percent). Yet only one-tenth of the world's population lives in sub-Saharan African countries.

\section{Figure 2:}

Global Annual Incidence of ST/S

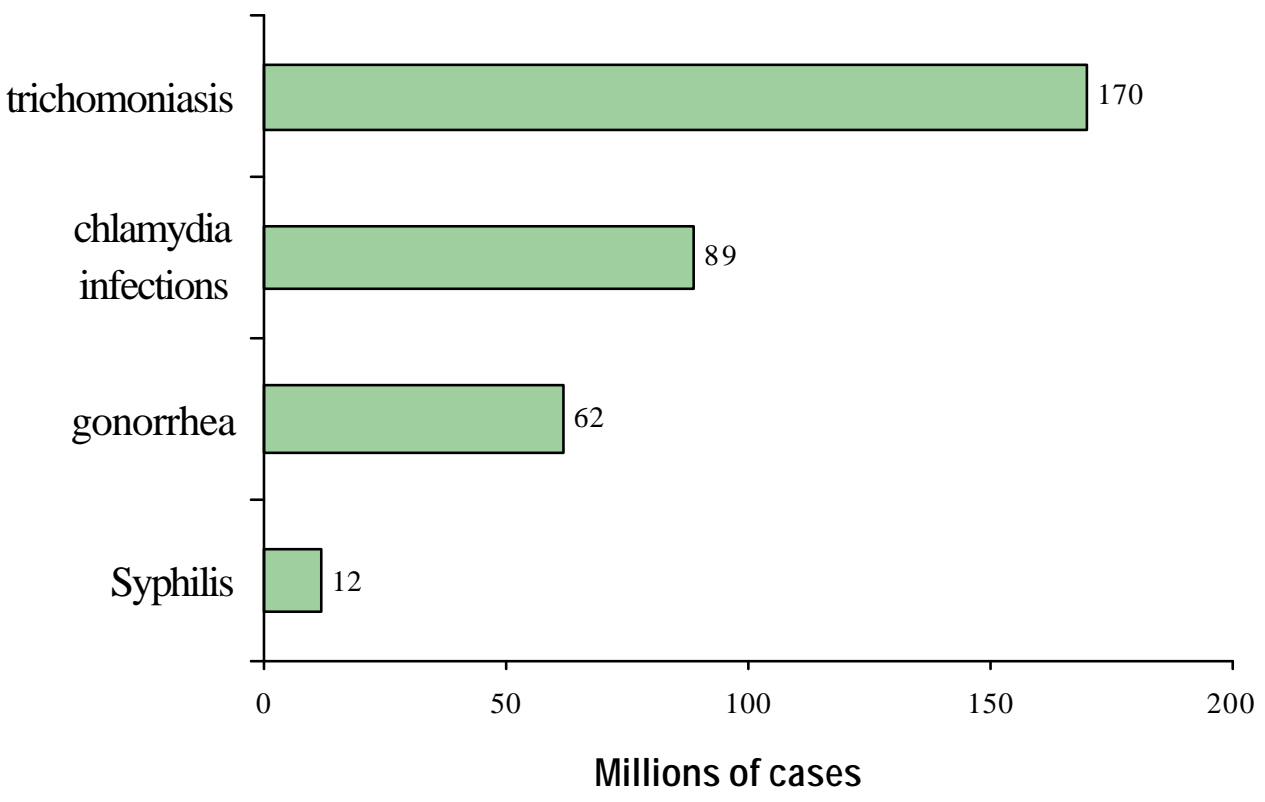

Kenya is one of the countries that are faced with high rates of HIV infection. The most recent data for Kenya indicate an adult HIV preval ence of 9 percent. While there have been over 80,000 reported AIDS cases as of June 1997, it is estimated that there are over 240,000 actual AIDS cases and roughly 1,400,000 additional HIV infections. Thehighest prevalencefound in sentinel surveillance sites is in Kisumu, with a rate of $34.9 \%$ in $1997 .{ }^{3}$ 
One contributing factor to the high rates of HIV infection in sub-Saharan A frica is the high prevalence of other STIs. Infection with someSTIs has been shown to increase the likelihood of contracting HIV through sexual contact. Studies have indicated a four times greater risk of becoming HIV-infected in the presence of a genital ulcer such as caused by syphilis and/ or chancroid and a significant though lesser increased risk in the presence of STIs such as gonorrhea, chlamydial infection and trichomoniasis. Efforts to improve the diagnosis and treatment of STIs have shown promise in addressing rates of HIV infection. A recent study in M wanza, Tanzania showed that improved STI treatment reduced HIV incidence by $42 \%$ in a rural population over a two-year period. ${ }^{4}$

One way to improve efforts to prevent the spread of STIs and HIV that has been proposed is to incorporate STI services into existing maternal and child health and family planning (MCH/ FP) services. This would reach women who typically do not receivesuch services. Moreimportant, it would potentially minimize the stigma associated with attending clinics that specifically treat STIs and to meet women's broader reproductive health needs. Following the International Conference on Population and Development (ICPD) in Cairo in 1994, therewas strong endorsement for a shift from family planning services to broader reproductivehealth services. The ICPD Program of Action identified a number of actions (see box below) to achieve the goal of preventing and reducing the spread of STDs, as well as providing treatment for STDs and their complications. ${ }^{5}$

ICPD PROGRAM OF ACTION:

\section{Preventing the spread of sexually transmitted diseases and HIV}

All reproductive health programs should increase their efforts to prevent, detect and treat sexually transmitted diseases and other reproductive tract infections, especially at the primary health-care level.

All health care providers, including all family planning providers, should be given specialized training in the prevention, detection of and counseling on sexually transmitted diseases, including HIV/AIDS, especially infections in women and youth.

Information, education and counseling on responsible sexual behavior and effective prevention of sexually transmitted diseases and HIV should become integral components of all reproductive and sexual health services.

All reproductive health care services should promote, supply and distribute high-quality condoms to reduce the spread of HIV/AIDS and sexually transmitted diseases. 
A s programs try to implement the Cairo agenda, there is a great deal of interest and effort in thearea of integrating STI services into MCH/ FP settings. However, there are many issues to be resolved in terms of identifying effective ways to manageSTIs within this setting. Theobvious benefits must be weighed against the restrictions of reality and limited resources to come up with models of integrated services that areboth effectiveand practical within different contexts.

What is integration?

Integration ( $n):$ a combination and coordination of separate and diverse elements or units into a more comple te or harmonious whole.

(Webster's $3^{\text {rd }}$ New International Dictionary, 1986)
Integration can take many forms, including incorporating different approaches for prevention, detection and treatment of STIS into $\mathrm{MCH} / \mathrm{FP}$ programs. There has been significant attention on improving case management of STIs through the adoption of syndromic management as an important aspect of integration. This technique relies on placing a client within a certain syndrome based on signs and symptoms and then the provider follows a flow chart to determine treatment for the primary causes of this syndrome. The main syndromes include vaginal discharge, lower abdominal pain, genital ulcer disease and urethral dischargein men.

The syndromic approach addresses the problem of how to provide services in resource poor settings where laboratory facilities do not exist and/ or are not feasible. It has been shown to work well for male urethral discharge and for genital ulcers in men and women, but the algorithm for vaginal discharge generally performs poorly for diagnosing cervicitis (either gonorrhea or chlamydia). Although the syndromic approach has been promoted recently for use in a variety of settings, this approach was developed for use with higher prevalence populations (i.e., in STD clinics) and the efforts at validating this approach in a lower preval ence setting, such as an MCH/ FP clinic, have shown disappointing results.

Critics of syndromic management point out that it can lead to the treatment of many false positives, i.e. women who do not really have an STI are diagnosed and treated as having one. N ot only does this increase cost to the program in terms of using drugs, but also it also potentially exposes the woman to the stigma and social repercussions associated with having an STI. Also, because so many women areasymptomatic, syndromic management will miss many of the true cases of STIs.

There has been a great deal of attention on the al gorithm for vaginal discharge, which has been the most problematic. One of the problems lies in its inability to differentiate between vaginitis and cervicitis since the two conditions are caused by different organisms requiring different treatments. Theformer, often caused by trichomoniasis, candidiasis or bacterial vaginosis, is much more common, while the latter, typically a result of gonorrhea or chlamydia, has more severe health effects, including PID and infertility. In Kenya, where it is 
estimated that roughly $80-90 \%$ of women with vaginal dischargeareinfected with candidiasis, trichomoniasis and/ or bacterial vaginosis, ${ }^{6}$ the approach has been to treat women with vaginal discharge for vaginitis and then tell them to return after one week if symptoms persist so that they can be treated for cervicitis. It is unknown how well this approach has worked; that is, do women return for follow-up treatment if they need it.

One way to adjust this approach is to incorporate risk assessment- that is, asking questions in a systematic manner about a person's social, economic, demographic, behavioral and clinical background and developing a risk score from this - to differentiate between RTIs that are sexually transmitted from those that are not. The WHO flow charts propose this, whereby if a woman complains of vaginal discharge, the provider then ascertains whether shehas complaints of lower abdominal pain or has a symptomatic partner or is positive for specific risk factors. If she answers yes to any of these, she is treated for cervicitis, while if the answer is no to all of them, she is treated for vaginitis.

Risk assessment can also potentially address the problem of missing women who are asymptomatic, as they never enter into the flow charts for syndromic management. Essentially, therearethreedifferent possibilities amongst $\mathrm{MCH}$ / FP clients who have an STI:

-women coming for M CH/FP services who also complain of symptoms suggestive of an STI;

-women who do not complain of symptoms, but have clinical signs of an STI that are identified through examination;

-W omen who have neither signs nor symptoms. The first group can be identified through syndromic management; the second group requires a pelvic exam so that a provider can look for signs such as cervical mucous or friability; in the absence of cheap, accurate, portable and fast tests, the third group is the most problematic to reach, though risk assessment has been proposed as a way to help identify asymptomatic cases.

An analysis of several integrated programs in the East and Southern Africa region found that risk assessment was not regularly carried out. Some of the main reasons identified for why providers were not routinely asking these questions were the following:

- clear instructions were not given during training;

- providers werenot given written guidelines or checklists to assist them in carrying out risk assessment;

- client record forms were not revised to accommodate this new information; and

-Providers said that they did not have enough time due to large client loads. ${ }^{7}$ 
But is risk assessment an improvement on thesyndromic approach in an $\mathrm{MCH}$ / FP setting? In a recent survey of STD risk assessment used among low-risk populations in east/ central Africa prepared by Family Health International $(\mathrm{FHI})$, the authors conclude the following:

"At first 6lush, riskassessment appears to be a relatively e asy way to integrate $S \mathcal{T} \mathcal{D}$ manage ment into family planning and $\mathcal{M C H}$ practice. Yet current evidence demonstrates its lack of effectiveness for at le ast cervicitis screening in low-prevalence populations. Unless risk assessments can be made more accurate, they will remain promising but ine ffective in lowprevalence settings, such as family planning and ante natal clinic at tendees."

Based on the constraints that face health services and the significant public health impact of STIs in sub-Saharan Africa, as in much of the world, it is essential that there be further work to improve integration efforts. 
Methodology and Objectives

In order to learn more about the process of integration in East and Southern Africa, the Population Council's A frica OR/ TA Project II, in collaboration with Pathfinder International, REDSO/ ESA, A frica Bureau of USAID, Data for Decision Making Project at Harvard and the Centers for Disease Control (CDC) in Atlanta, has developed a methodology for conducting case studies of programs and projects that have adopted an integrated approach to provide STI, HIV/ AIDS and MCH/ FP services. The methodology involves four activities: review of available data and reports, in-depth interviews with a management team, a modified Situation Analysis and guided group discussions. This methodology has been used to carry out four casestudies in Kenya ${ }^{9}$, U ganda ${ }^{10}$ and Botswana. ${ }^{11}$ The findings from these casestudies were also synthesized into one comprehensive report. ${ }^{12}$

The Nakuru Municipality and the STI/HIVIAIDS Project

The $\mathcal{N a k u r u}$ Municipality is located 160 kilometers northwest of

$\mathcal{N}$ airobi along the Trans-Afric a highway and the Kenya/Uganda Railway, both of which link the Mombas a seaport and several East and Central $\mathcal{A}$ frican countries. This increases the risk of its residents for $\mathcal{S} I s$ and $\mathcal{H} I \mathcal{V} / \mathcal{A} I \mathcal{D S}$. Data from the $\mathcal{N a t i o n a l} S$ urveillance show that the prevalence of $\mathcal{H I} \mathcal{V}$ infection increased from $9.9 \%$ in 1990 to $27.2 \%$ in 1995. Data of other $\mathcal{S} \mathcal{T} I$ s are not readily available but reports from the Municipal Council Health De partment show that STIs account for a large proportion of the outpatient clinic visits in all the ir five clinics.

To respond to these concerns, the Municipal Council has been participating in a collaborative project with the Nairobi City Council and the Universities of $\mathcal{N}$ airobi and Manitob a funded jointly by the Government of Kenya and Canadian International Development Agency $(C I D \mathcal{A})$ since 1990. The long-term goal of this project is to reduce the incidence of $\mathcal{S} \mathcal{T} I s$ and $\mathcal{H} I \mathcal{V} / \mathcal{A} I \mathcal{D S}$ through strengthening the manage ment of $\mathcal{S} \mathcal{T} I s$ and $\mathcal{H} I \mathcal{V} / \mathcal{A} I \mathcal{D S}$ at the health facilities and establishing sustainable community based $\mathcal{S} I / \mathcal{A} I \mathcal{D S}$ control activities.

At the clinic level, the project facilitated training of staff in the use of the syndromic approach to detect and manage $S \mathcal{T} I s$. It also established a reference laboratory at one of the clinics for use in diagnosing $S \mathcal{T} I s$ in clients who were not responding to drugs prescribed using the syndromic approach and for testing antenatal clients for syphilis infection. The project also provided drugs for treating $S \mathcal{T} I s$ and condoms. At the community level, the project supports a peer education program for commercial sex workers and carries out IEC activities for in-school youth and factory employees within the municipality. 
The study reported here consisted of two components. First, a case study was conducted to assess the current state of integrated services in Nakuru. Based on the findings and some of the major issues identified, an OR study was then developed to test ways to improve integration efforts in Nakuru and to learn regional lessons from this work.

a) Case study. The Nakuru Municipal Council had been involved in an STI Project for a number of years (see previous box). It was identified as one of the projects for a case study.

Figure 3:

HIV Prevalence in Nakuru, Kenya

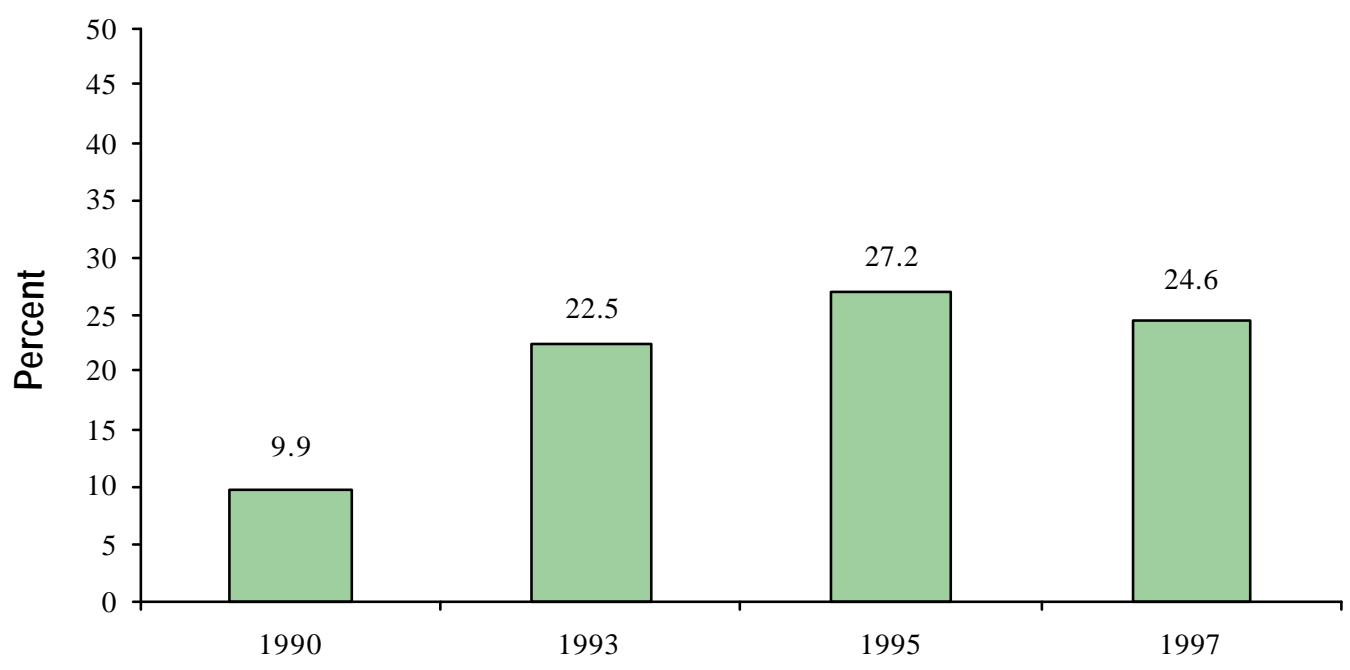

The casestudy was carried out in 1995, after fiveyears of project implementation and focussed on examining the clinic level aspects of the project. The major findings included the following: ${ }^{13}$

- Staff do not undertake STI/HIV risk assessment, clinical evaluation and counseling for most of the clients attending the clinics for M CH/FP services. Even though staff sometimes ask risk-related questions, such as number of sex partners, this is done rarely and is not done in a systematic manner to manage clients.

- Staff were required to use diagnostic algorithms devel oped for use primarily in STI clinics without any adaptations, yet their sensitivity, specificity and positive predictive values have not been well studied in MCH/FP clinics and other populations where the prevalence of STIs is low.

- Staff did not have appropriate checklists for use when undertaking STI risk assessment, case detection and counseling. In addition the client record forms had not been modified to cater for the new information collected during STI and HIV / A ID S risk assessment and case detection procedures.

- M ost of the facilities lacked some of the basic equipment and supplies required to provide good quality M CH/FP and STI/HIV/AIDS services. 
- A the time of the case study no cost analysis/effectiveness studies had been undertaken that would help in the development of sustainability strategies given that the project was heavily donor supported.

Steps were taken to address some of the issues raised in the case study, including theprovision of necessary equipment, the development of a checklist, conducting a counseling course for staff, planning for the incorporation of risk assessment and the development of an OR study.

b) O R study to improve the management of STIs. Based on the findings of the case study, an OR study was developed to contribute to a reduction in the prevalenceand spread of STIs among women receiving family planning and maternal and child health services from the Nakuru Municipal Council health clinics. Thestudy had the following objectives:

1. to determine the validity of the current syndromic approach being used for the management of vaginal discharge in $\mathrm{MCH}$ / FP services

2. To compare the effectiveness of the current syndromic approach with a modified approach including risk assessment

3. to predict the effectiveness of using risk assessment as a tool in STI case detection

4. $\quad$ to provide estimates of the prevalence of selected STIs among an $\mathrm{MCH} / \mathrm{FP}$ population

Family planning and new antenatal clients were recruited into thestudy from the five NMC clinics. The study involved obtaining the following threetypes of information from each woman who was enrolled in the study:

- Findings from the medical examination including symptoms and clinical signs;

- R isk factor information obtained by providers through the use of a checklist; and

- Laboratory results from specimens collected during the examination.

The data collection was guided by the use of a checklist. This checklist was developed initially in Botswana as part of its integration program, and was then modified and adapted for the Nakuru situation by a team of clinicians and researchers in Nakuru. The checklist was also used for a similar OR study in Zimbabwe, again with modifications for the local context. The use of a similar data collection instrument in different settings will allow for later comparative analyses.

\section{Field Work and Data Collection}

Fieldwork began on March 16, 1998 and continued for four months, ending on July 17, 1998. Prior to beginning fieldwork, there was a five-day training for the providers who would be involved in the study. A total of 18 nurses 
were identified by the $\mathrm{N}$ akuru Municipal Council to be trained, at an average of 3 or 4 from each clinic. The nurses were divided into two groups and each attended training for two days, followed by one day where the entire group was brought together.

During training, two trainers from Nakuru provided an overview of the signs and symptoms of various STIs and syndromic management. Providers had al ready been trained in syndromic management, but this training was conducted as a refresher course. In addition, the providers weretrained to usethechecklist for data collection. The checklist was modified during the training with input from the providers to meet clinic needs.

Five researchers were also trained to assist in the data collection. A researcher was based at each clinic to manage logistics and to help the providers in completion of the checklist and transfer of information from the checklists onto the client cards. Researchers were given a three day training to familiarize themselves with the study, the clinics and the clinic staff.

A study coordinator who was based at one of the clinics coordinated all fieldwork activities. He was responsible for the overall logistics for data collection, including the following: providing all necessary supplies to the dinics; collecting and handling transport of specimens to Nairobi each day; collecting checklists from each clinic; receiving and processing thelaboratory results from Nairobi to allow for notification of clients of their results; and managing all problems that occurred during the conduct of the field work.

The nurses recruited new antenatal clients and both new and revisit family planning clients into the study. Because of the low numbers of new clients, it was necessary to also recruit revisit FP clients to obtain a large enough sample size to assess effectiveness. First, the nurses informed clients about the study and its purpose and then read an informed consent statement. If verbal consent was obtained, then the client was recruited into thestudy. Clients wereassured that their refusal to participate in the study would have no impact on them or theservices that they received. Thenursethen completed the checklist including the collection of specimens for laboratory tests.

During the course of the fieldwork, a number of meetings were held with providers. This enabled the group to share experiences, learn from each other and make any necessary modifications based on problems encountered during the fieldwork. Some of the problems encountered were:

- Lack of water or other supplies, such as disinfectant, gloves or cotton wool. Without supplies necessary for proper infection prevention, services could not be offered. This happened at all of the clinics at various points during the study.

- Staff strikes. At a number of points during the study, the providers went on strike over various issues with the $\mathrm{N}$ akuru $\mathrm{M}$ unicipal Council. This led to disruptions in services and ther efore in data collection and was one of the factors in lengthening slightly the period of data collection.

- Staff morale. Some providers felt that the additional work that they needed to undertake for data collection, i.e. completion of the checklists, was too much given the 
timethey had available. Someal so felt that they were not being properly compensated given this extra work.

- Logistical problems. Because of the complicated logistics involved in sending specimens for testing in $\mathrm{N}$ airobi, therewere often delays in sending results to $\mathrm{N}$ akuru.

\section{Laboratory Procedures}

Laboratory tests were conducted at the Department of Medical Microbiology at the University of Nairobi. The Department prepared kits with the items necessary for specimen collection and transport. A kit was made up of a ziploc bag and included in-pouch kits (for testing for trichomoniasis), urine bottles, swabs and slides. Each kit, as well as each item in the kit, was labeled with a sticker with a unique study number. In addition, several additional stickers with the same study numbers were in each kit in order to label the checklist so that it could be matched with the lab results. Each clinic was allotted a different set of numbers. A nother item required for specimen collection was the transport medium for candida. Because this needed to be refrigerated, the Department sent batches of the prepared media at regular intervals to the study coordinator. On a daily basis, each clinic was provided with ice packs for their cooler to keep the urine samples cool before they were put into a larger cooler for transport to Nairobi. At the end of each day, specimens were collected by the study coordinator and brought to one clinic where they were picked up by a courier service for transport to Nairobi.

Thefollowing tableindicates the reproductivetract infections that weretested for, the specimens that were collected and the tests performed.

\begin{tabular}{l|l|l} 
& Specimen & Test \\
\hline Gonorrhea & Urine & Ligase Chain Reaction (LCR) \\
Chlamydia & Urine & LCR \\
Trichomoniasis & High vaginal swab (HVS) & in-pouch media \\
Candidiasis & HVS & gram stain \\
Bacterial vaginosis & HVS & gram stain
\end{tabular}

1. Bacterial vaginosis: smears were made in the clinics in Nakuru and were transported to the laboratories in Nairobi where they were subjected to gram's staining technique. Cluecells, gardnarella vaginosis and bacteroides or morbilancus were looked for.

2. Candidiasis: was identified by demonstration of candida organisms grown on saubouranuds dextrose agar medium. The characteristic colonies of the organism were then subjected to gram's stain technique, where gram positive budding yeast was used to decide on the presence of candida infection.

3. Trichomoniasis: high vaginal swabs were inoculated in the In-Pouch Media described by BIOMED Diagnostics, Inc., San Jose, CA standards 
for the culture of $\mathrm{T}$. vaginalis. The cultures were examined under the microscope after incubation at $37^{\circ} \mathrm{C}$ for between $48-72$ hours. Recov ery of viable of T. vaginalis organisms was considered as evidence of infection.

4. Gonorrhea: N eisseria gonorrhea was detected using the Ligase Chain Reaction (LCR) amplification technology in the LCX probe system. - a method designed by A bbot Laboratories, IL, USA. The assay is used in direct qual itative detection of a specific nucleic acid sequence in the Opa gene of $\mathrm{N}$ eisseria gon orrhea in urine specimens from symptomatic and asymptomatic subjects.

5. Chlamydia: Chlamydia trachomatis was detected using the Ligase Chain Reaction (LCR) amplification technology in the LCX probe system. - a method designed by A bbot Laboratories, IL, USA. The assay is used in direct qual itative detection of plasmid DNA of $\mathrm{C}$. trachomatis in urine specimens as an aid in the diagnosis of $\mathrm{C}$. trachomatis infection.

\section{Data Entry and Analysis}

Data entry was carried out using the Epilnfo 6.02 software with matchingscreen formats to the questionnaires. The double entry procedure was used for validation of the data entry. The following dependent variables were created

- cervicitis: was the occurrence of gonorrhea or chlamydia or both.

-vaginitis: the occurrence of trichomoniasis, candida, and bacterial vaginosis alone or in any combination.

-STI: the presence of gonorrhea or chlamydia or trichomoniasis in any combination.

-non STI: the presence of candida or bacterial vaginosis or both.

- any infection: the presence of any of the above four dependent variables-cervicitis, vaginitis, STI and non-STI.

The dependent variables were transformed to nominal categories $0=$ negative and $1=$ positive. Using SPSS Version 8.0 software, univariateanalysis using the two by two tables was done for all the independent variables included in the history, clinical examination and risk assessment. The independent variables were assessed for significance of association with the dependent variables using crudeODDSRATIOs (OR) and P-values. Thesensitivity, specificity and positive predictive value were computed for those independent variables that were significantly associated (at the $95 \%$ confidence interval) with the dependant variables.

A djusted $O R$ and $p$-values resulting from a logistic regression were estimated including the $95 \%$ confidenceintervals. Theindependent variables wereincluded in the logistic regression model if they were observed to have an association with the dependent variables at the $10 \%$ level of significance in the univariate analysis. Qualifying independent variables were subjected to a stepwise 
multiple logistic procedure using the backwards selection procedure. The model that explained the most variability in the dependent variable and also had the best sensitivity, specificity and positive predictive value was selected.

To determine the relative importance of each of the variables in each model, we calculated the standardized coefficients for each variable. The absolute value of the standardized coefficient was considered to represent the relative importance of each variable in relation to the other variables in the model. 


\section{Characteristics of Sample}

The socio-demographic characteristics of the samples of ANC and FP clients differed somewhat (Table 1). For example, on average the FP clients were about three and a half years older than the ANC clients and had one more living child. The majority of both ANC and FP clients were married (84.2 and 86.4 percent, respectively), though a larger proportion of ANC clients were single (10.7 percent vs. 6.5 percent of FP clients). Years of education were similar for both groups (nine years) as was the number of desired children (roughly 3 , on average).

\section{Table 1:}

Socio-demographic characteristics of clients

\begin{tabular}{|c|c|c|}
\hline Characteristic & FP clients ( $n=906)$ & Antenatal clients $(n=815)$ \\
\hline Age & $\begin{array}{l}\text { mean }=\mathbf{2 7 . 6} \\
\text { median }=\mathbf{2 6 . 5}\end{array}$ & $\begin{array}{r}\text { mean }=\mathbf{2 4 . 1} \\
\text { median }=\mathbf{2 3}\end{array}$ \\
\hline$<20$ & 6 & 21 \\
\hline $20-24$ & 29 & 38 \\
\hline $25-29$ & 32 & 25 \\
\hline $30+$ & 33 & 16 \\
\hline \multicolumn{3}{|l|}{ Marital status } \\
\hline Married (monogamous) & 77.6 & 73.8 \\
\hline Married (polygamous) & 8.8 & 10.4 \\
\hline Single (never married) & 6.5 & 10.7 \\
\hline Cohabiting & 1.3 & 3.9 \\
\hline Divorced/separated & .5 & .9 \\
\hline Widowed & .8 & .2 \\
\hline \multirow[t]{2}{*}{ Education (years) } & mean $=9.1$ & mean $=\mathbf{8 . 8}$ \\
\hline & median = 8 & median = 8 \\
\hline \multicolumn{3}{|l|}{ Religion } \\
\hline Christian & 70 & 67.5 \\
\hline Catholic & 25 & 23 \\
\hline Muslim & 1.2 & 3.4 \\
\hline Other & 3.9 & 6 \\
\hline \# of pregnancies & mean $=\mathbf{2 . 8}$ median $=\mathbf{2}$ & mean $=\mathbf{2 . 3}$ median $=\mathbf{2}$ \\
\hline \# of living children & mean $=2.5$ median $=2$ & mean $=1.1$ median $=1$ \\
\hline \# of desired children & mean $=\mathbf{3} .4$ median $=\mathbf{3}$ & mean $=\mathbf{3 . 1}$ median $=\mathbf{3}$ \\
\hline
\end{tabular}

Data on table 2 shows the prevalence of the various RTIs, as well as different combinations of infections, based on laboratory testing. Some of this information is highlighted in figure 4 as well. A strikingly large proportion of 
clients had at least one infection of the five for which laboratory tests were performed: 59 percent of ANC clients and about half (49.8 percent) of FP clients. Likewise, a substantial number of women had an STI (chlamydia and/ or gonorrhea and/ or trichomoniasis): 21.1 and 14.2 percent of ANC and FP clients, respectively. This is quitestriking in a population that is usually referred to as "low risk" or "low prevalence".

Table 2:

Prevalence of RTIs among study population

\begin{tabular}{l|c|c} 
RTI or combinations of RTIS & FP clients ( $\mathbf{n = 9 0 6 )}$ & ANC clients ( $\mathbf{n = 8 1 5 )}$ \\
\hline Gonorrhea & 2.6 & 3.7 \\
\hline Chlamydia & 5.7 & 7.1 \\
\hline Trichomoniasis & 8.0 & 14.4 \\
\hline Candidiasis & 16.7 & 33.9 \\
\hline Bacterial Vaginosis & 33.4 & 29.5 \\
\hline $\begin{array}{l}\text { Any RTI } \\
\text { (any of the above five infections) }\end{array}$ & 49.8 & 59 \\
\hline $\begin{array}{l}\text { Any STI (gonorrhea and/or } \\
\text { chlamydia and/or trichomoniasis) }\end{array}$ & 14.2 & 21.1 \\
\hline $\begin{array}{l}\text { Cervicitis } \\
\text { (gonorrhea and/or chlamydia) }\end{array}$ & 7.5 & 9.4 \\
\hline $\begin{array}{l}\text { Vaginitis (trichomoniasis } \\
\text { and/or candidiasis and/or BV) }\end{array}$ & 46.8 & 55.5 \\
\hline
\end{tabular}

It is notable that the prevalence of most RTIs is higher among antenatal clients as compared with family planning clients. This might partially be accounted

Figure 4: Prevalence of various combinations of RTIS

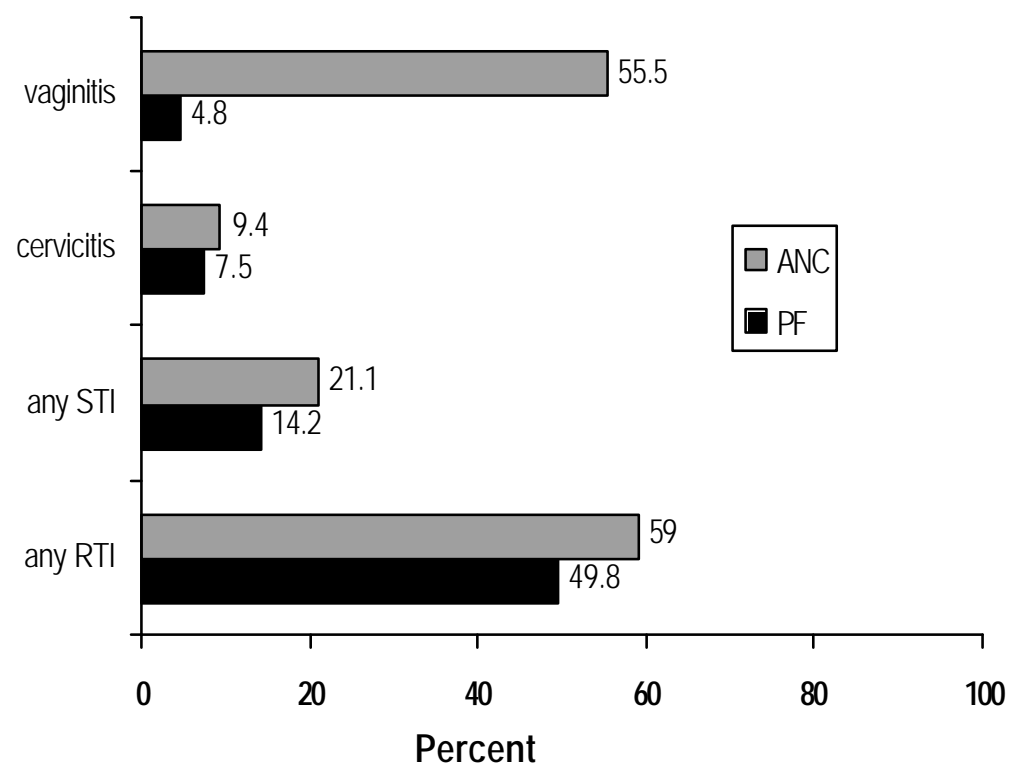
for by the fact that ANC clients were younger and a slightly higher proportion were single, both factors that are commonly cited as increasing risk for an STI. In addition the higher prevalence of candidiasis, which accounts for much of the difference, is to be expected among pregnant women. This is because during pregnancy there is an increase in estrogen levels, poor sugar metabolism and changes in the vaginal $\mathrm{PH}$, all of which favor the growth of candida. 
Much attention has been placed on cervical infections because of the serious heal th outcomes that can occur when these infections are not treated, such as PID and infertility. In our study population, cervical infections havea relatively low prevalence as compared with vaginal infections. Recently, however, there has been evidence indicating that vaginal infections should be given more attention, as noted in the following:

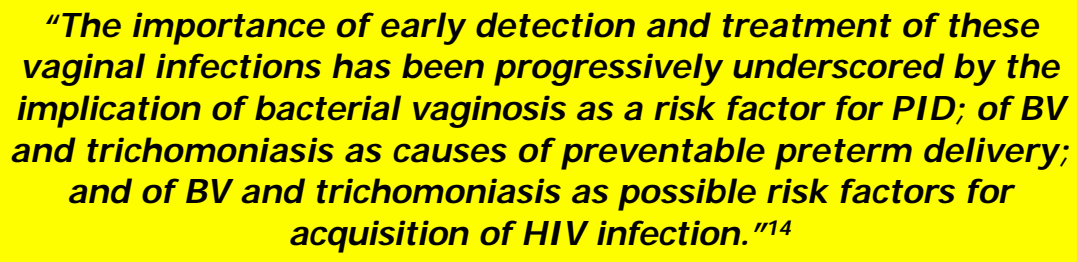

With roughly onethird of both FP and ANC clients testing positive for BV, it is clearly important in light of the potential serious health impacts that this be addressed more effectively.

A number of women had multipleinfections; 23 percent of ANC clients and 13 percent of FP clients had 2 or more infections. If we only look at gonorrhea, chlamydia, trichomoniasis and bacterial vaginosis, leaving out candidiasis, the breakdown for number of infections looks similar for both ANC and FP clients (Table 3). This shows that some of the difference between the prevalence of infections among ANC and FP clients is due to candidiasis, which, as noted above, is generally more common among pregnant women. This breakdown also shows that 16 percent of ANC and nine percent of FP clients had only candidiasis; of the five infections, for which lab tests were conducted, this is probably the one with the least serious health consequences.

\section{Table 3:}

Proportion of ANC and FP clients with multiple infections

\begin{tabular}{l|c|c|c|c} 
& \multicolumn{2}{|c|}{ For all $\mathbf{5}$ infections } & \multicolumn{2}{c}{$\begin{array}{c}\text { For } 4 \text { infections } \\
\text { (without candidiasis) }\end{array}$} \\
\hline \# of infections & ANC & FP & ANC & FP \\
\hline Zero & 41 & 50 & 57 & 59 \\
\hline One & 36 & 37 & 33 & 34 \\
\hline Two & 19 & 11 & 8 & 6 \\
\hline Three or More & 4 & 2 & 1 & 1 \\
\hline
\end{tabular}


Figure 5 shows the ever use of the most common contraceptive methods by both FP and ANC clients. Just over one-quarter (27 percent) of the FP clients recruited into the study were new clients, 12 percent were classified as restarting, whiletheremainder werecoming for revisit or resupply. Comparing family planning clients and only those antenatal clients who had ever used modern family planning methods prior to the index pregnancy $(271,33 \%)$ shows that antenatal clients were more likely to have used the combined pill compared with family planning clients. However, family planning clients were morelikely to have used the injectable. This observation may represent a change in the pattern of contraceptive use over time since family planning clients represent current users while antenatal clients represent past use. Similarly in the 1998 Kenya Demographic and Health Survey, injectables (12 percent) have now overtaken the pill (9 percent) as the most widely used modern method of contraception. ${ }^{15}$

\section{Figure 5:}

Ever use of various contraceptive methods by FP and ANC clients

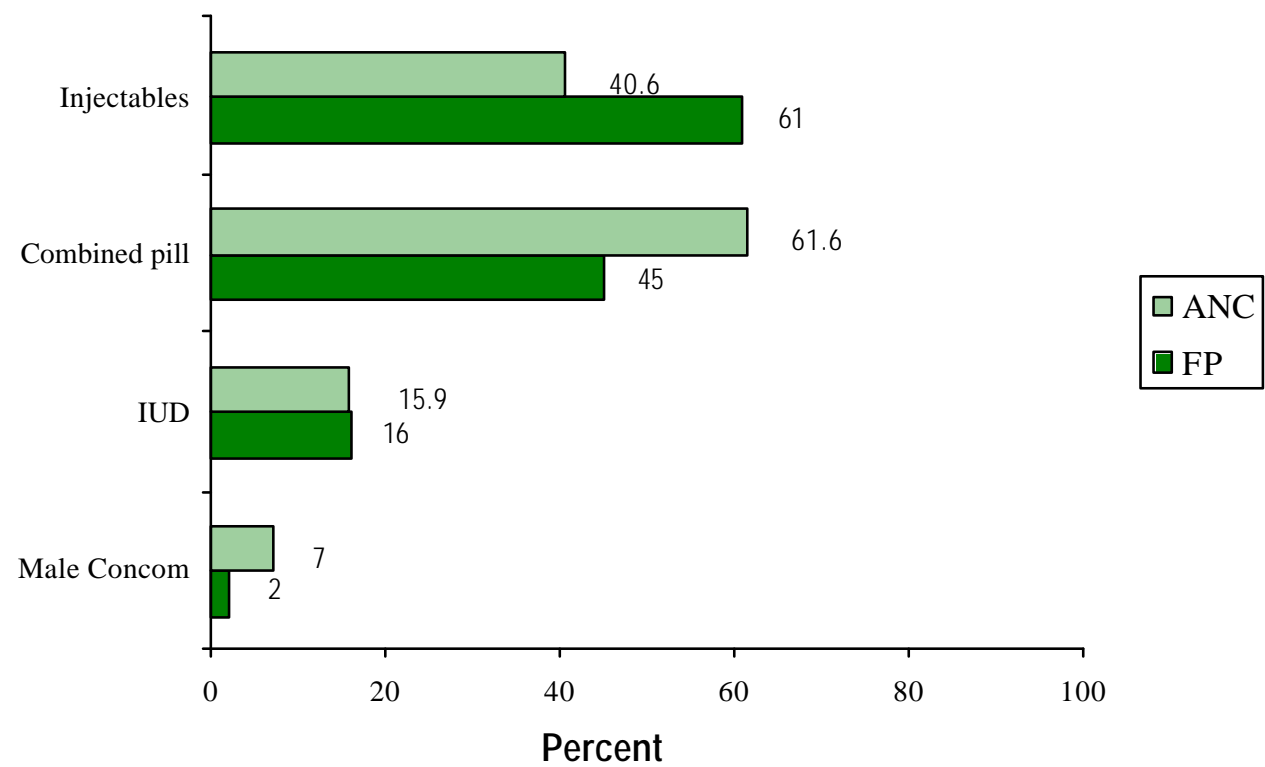

Few women from either group ( $2 \%$ and $7 \%$ for family planning and antenatal clients, respectively) had ever used a male condom. The figures for family planning clients are low compared to the figure in the $1998 \mathrm{DHS}$, where 9.4 percent of women stated that they had ever used the condom. It should be noted that our figure of two percent for the family planning clients is possibly an undercount for various reasons, including the fact that sometimes a woman does not report her partner's method and that sometimes people perceive of the condom as a means of protecting against disease rather than pregnancy. N onetheless, these low figures are particularly troubling given the high rates of both HIV and STIS. 


\section{Symptoms}

Providers asked women about a number of symptoms that could indicate the presence of an STI during the medical history-taking portion of their exam. The results of this are shown in table 4. The provider asked each woman whether she currently had each of the symptoms.

\section{Table 4:}

Presence of symptoms in woman, as reported in medical history taking

\begin{tabular}{l|c|c} 
Symptom & Family Planning clients & Antenatal clients \\
\hline lower abdominal pain & 5.5 & 7.9 \\
\hline yellow discharge & 1.9 & 3.5 \\
\hline blood stained discharge & 1.4 & 0.9 \\
\hline foul smelling discharge & 3.3 & 6.3 \\
\hline Increased amount of discharge & 4.7 & 12.6 \\
\hline post coital bleeding & 1.8 & 1.0 \\
\hline pain during sexual intercourse & 3.2 & 6.0 \\
\hline pain on passing urine & 2.3 & 5.1 \\
\hline genital ulcers/ sores & 1.4 & 1.6 \\
\hline painful swellings in the groin & 0.8 & 0.5 \\
\hline warts in the genital area & 0.1 & 0.5 \\
\hline bleeding between periods/ spotting & 2.0 & 1.4 \\
\hline dysmenorrhea & 12.9 & $\mathrm{~N} / \mathrm{A}$ \\
\hline
\end{tabular}

Most of the symptoms were more common among ANC clients, however all the prevalence figures were fairly low, especially in comparison with the prevalence of the RTIs based on laboratory testing. Overall, 25 percent of ANC clients and 23 percent of FP clients had at least one symptom (of a list of 12 or 13 symptoms, respectively - ANC clients were not asked about dysmenorrhea since they were pregnant). Of women with an RTI based on lab diagnosis, only 29 percent and 23 percent of ANC and FP clients, respectively, had at least onesymptom. This is strong evidence of the high proportion of infected women who are asymptomatic.

In addition, women were asked about the presence of various symptoms that might beindicative of an STI in their partners. Very few women indicated that their partners had any of thesymptoms that wereasked about (Table5). Overall, for both FP and ANC clients, just five percent answered yes to the presence of at least one of the nine symptoms asked about in their partner. Between seven and eleven percent of antenatal clients and from 11 to 15 percent of family planning clients answered "don't know" when asked about partners' symptoms. Though the proportion answering "don't know" is fairly low, we have no way in this study to assess the accuracy of women's reporting of their partners' symptoms. 
Table 5:

Presence of symptoms in woman's partner, as reported in risk assessment

\begin{tabular}{l|c|c} 
Symptom & $\begin{array}{c}\text { Family Planning } \\
\text { clients }\end{array}$ & $\begin{array}{c}\text { Antenatal } \\
\text { clients }\end{array}$ \\
\hline$\bullet$ & .9 & .5 \\
\hline - purulent urethral discharge & 1.2 & .7 \\
\hline - pain on passing urine & .9 & .4 \\
\hline - wound/ sores in the genital area & .7 & .5 \\
\hline - swellings in the groin & .4 & .1 \\
\hline - wounds/ sores in the mouth & .2 & .1 \\
\hline - skin rash & .4 & .7 \\
\hline - treatment for STls & 2.1 & 1.6 \\
\hline - antibiotic treatment & 3.4 & 3.4 \\
\hline
\end{tabular}

\section{Clinical Signs}

Overall, 40 percent of ANC clients and 37 percent of FP clients had at least one clinical sign (of 16 possible clinical signs). Of women who had a RTI, based on laboratory diagnosis, only 43 percent and 37 percent of ANC and FP clients, respectively, had at least one clinical sign. A gain, this points to the high proportion of women with an RTI who show no clinical signs during examination. There is a higher proportion of ANC women with signs of vaginal or cervical discharge(Table6). For example, 8.1 percent of ANC clients as compared with 1.7 percent of FP clients had white/ curdy discharge. The differences in prevalence of vaginal discharge between family planning clients and antenatal clients is most probably due to the hormonal, biochemical and metabolic changes that occur during pregnancy described earlier. 
Table 6:

Presence of signs of infection, as noted by providers during pelvic examination

\begin{tabular}{|c|c|c|}
\hline Clinical sign & Family Planning clients & Antenatal clients \\
\hline \multicolumn{3}{|l|}{ Inspection (vulva/buttocks/groin) } \\
\hline •rashes/ vesicles & 00.4 & 001 \\
\hline - ulcers/ wounds/ sores & 00.4 & 00.7 \\
\hline •warts & 00.2 & 00.2 \\
\hline - swellings in the groin & 00.1 & 00.2 \\
\hline - clear discharge & 17.9 & 14.3 \\
\hline - white/ curdy discharge & 01.7 & 08.1 \\
\hline - greenish discharge & 000 & 00.1 \\
\hline •yellow discharge & 00.9 & 03.7 \\
\hline \multicolumn{3}{|l|}{ Speculum examination } \\
\hline •warts on vagina wall & 0.1 & 00.6 \\
\hline •curdy discharge in vagina & 1.6 & 06.8 \\
\hline - cervical warts/ polyps & 0.3 & 00.5 \\
\hline - discharge from cervical Os & 4.4 & 14.3 \\
\hline - cervical erosion/ ulcers & 1.0 & 02.3 \\
\hline \multicolumn{3}{|l|}{ Digital examination } \\
\hline •cervical excitation & 15.7 & 10.8 \\
\hline •tenderness in adnexia & 00.1 & 01.3 \\
\hline • ovarian masses & 000 & 00.1 \\
\hline
\end{tabular}

\section{Risk Factor Information}

As part of the checklist, providers asked a number of questions regarding potential risk factors. This included issues such as whether the woman or her partner's employment involved staying away from home, whether she or her partner drink alcohol, perception of risk, and various questions on sexual behavior (see appendix 1 and 2). Data on table 7 show the preval ence of these risk factors among FP and ANC clients. 
Table 7:

Presence of risk factors in family planning and antenatal clients.

\begin{tabular}{|c|c|c|}
\hline Risk Factor & $\begin{array}{l}\text { Family } \\
\text { Planning clients }\end{array}$ & $\begin{array}{l}\text { Antenatal } \\
\text { clients }\end{array}$ \\
\hline $\begin{array}{l}\text { woman's employment involves staying } \\
\text { away from home }\end{array}$ & 6.7 & 5.3 \\
\hline $\begin{array}{l}\text { woman has stayed away from home } \\
\text { for more than a month in the } \\
\text { past three months }\end{array}$ & 6.5 & 6.5 \\
\hline $\begin{array}{l}\text { woman has stayed away from home } \\
\text { in the past four weeks }\end{array}$ & 7.1 & 9.8 \\
\hline $\begin{array}{l}\text { spouse's/ regular partner's employment } \\
\text { involves staying away from home }\end{array}$ & 22 & 19.9 \\
\hline $\begin{array}{l}\text { spouse has stayed away from home } \\
\text { for more than a month } \\
\text { in the past three months }\end{array}$ & 13.8 & 11.2 \\
\hline $\begin{array}{l}\text { spouse has stayed away from } \\
\text { home in the past four weeks }\end{array}$ & 16.6 & 19.5 \\
\hline spouse drinks alcohol at least once a week & 41 & 30.9 \\
\hline woman drinks alcohol at least once a week & 5.7 & 2.1 \\
\hline $\begin{array}{l}\text { woman thinks that her partner has } \\
\text { sex with other women }\end{array}$ & 14.1 & 8.5 \\
\hline $\begin{array}{l}\text { woman thinks she is at increased } \\
\text { risk of getting an STD }\end{array}$ & 17.1 & 9.2 \\
\hline $\begin{array}{l}\text { woman thinks she is at increased } \\
\text { risk of getting HIV infection }\end{array}$ & 14.2 & 7 \\
\hline $\begin{array}{l}\text { woman thinks she might currently } \\
\text { have an STD }\end{array}$ & 2.3 & 1.7 \\
\hline $\begin{array}{l}\text { woman has been treated or sought } \\
\text { treatment for an STD in the past } 12 \text { months }\end{array}$ & 5.7 & 4.7 \\
\hline $\begin{array}{l}\text { woman has had more than one } \\
\text { sexual partner in the past three months }\end{array}$ & 2.6 & 1.7 \\
\hline $\begin{array}{l}\text { woman has had more than one } \\
\text { sexual partner in the past four weeks }\end{array}$ & 2.6 & 1 \\
\hline $\begin{array}{l}\text { partner used a male condom } \\
\text { that last time she had sexual intercourse }\end{array}$ & 7.2 & 3.6 \\
\hline $\begin{array}{l}\text { woman used intravaginal preparations } \\
\text { for the purpose of drying or constricting the } \\
\text { vagina for sexual intercourse in the past } \\
\text { three months }\end{array}$ & 1.1 & .7 \\
\hline
\end{tabular}


Many of the factors, such as drinking frequency, perception of risk of STI or HIV infection, treatment for STIs or multiple partners, aremorecommon among FP clients as compared with ANC clients, yet this group showed a lower prevalence of all RTIs (except for BV, which was roughly equivalent). Overall, 59.1 percent of FP clients and 66.7 percent of ANC clients answered yes to at least one risk factor.

A number of women (17.1 and 9.2 percent of FP and ANC clients, respectively) said that they felt that they were at increased risk of getting an STI. It is interesting to note the reasons women gave for this feeling. One of the most common reasons cited was that the men in their lives put them at risk. The following quotes highlight this sentiment:

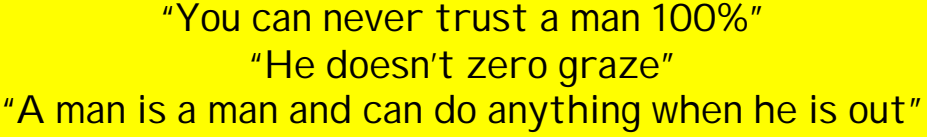

Some specifically mentioned that they knew or suspected that their partners had other sexual partners, while some felt that because he went out and drank he then often ended up with other women. This highlights the need for programs to reach men more effectively in education and counseling regarding STIs and behavior change.

\section{Effectiveness of Syndromic Management}

Staff at the Nakuru Municipal Council clinics had been trained in the use of standardized clinical algorithms for diagnosing and deciding management of clients presenting with symptoms suggestive of STIs. Syndromic diagnoses were made in 51 and 147 of the family planning and antenatal clients recruited in thestudy, respectively. Table 8 shows the proportion of family planning and antenatal clients that received diagnosis for the different STI syndromes. It should be noted that not all women attending for these services were recruited into the study, and therefore this does not necessarily indicate all women who were diagnosed through syndromic management at the clinics. Nonetheless, the limited proportion of these women diagnosed through syndromic management is particularly striking given the high prevalence of RTIs among this population.

\section{Table 8:}

Syndromic diagnoses made by providers

\begin{tabular}{l|c|c} 
Syndrome & $\begin{array}{c}\text { Family Planning clients } \\
(\mathrm{n}=906)\end{array}$ & $\begin{array}{c}\text { Antenatal clients } \\
(\mathrm{n}=815)\end{array}$ \\
\hline Vaginal discharge & $4 \%(36)$ & $13 \%(106)$ \\
\hline Genital ulcer & $.3 \%(3)$ & $1 \%(8)$ \\
\hline Lower abdominal pain & $1.1 \%(10)$ & $2.9 \%(24)$ \\
\hline Bubo (swelling in the groin) & - & $.5 \%(4)$ \\
\hline Warts & $.2 \%(2)$ & $.6 \%(5)$
\end{tabular}


During thestudy, clinic staff recorded all information obtained from the client on history and clinical examination using a standardized checklist. A review of these checklists showed that not all clients who complained of and/ or werefound to have abnormal vaginal discharge on clinical examination were diagnosed as having vaginal discharge syndrome and managed accordingly. A syndromic diagnosis of vaginal discharge was more likely if the woman complained of vaginal discharge and was found to have one on clinical examination (figure 6). It is not clear from this study as to why a syndromic diagnosis was madefor some of the women complaining of vaginal discharge and those found to have an abnormal vaginal discharge and not the others.

\section{Figure 6:}

Proportion of clients with symptoms and/or signs of vaginal discharge for whom staff made syndromic diagnosis

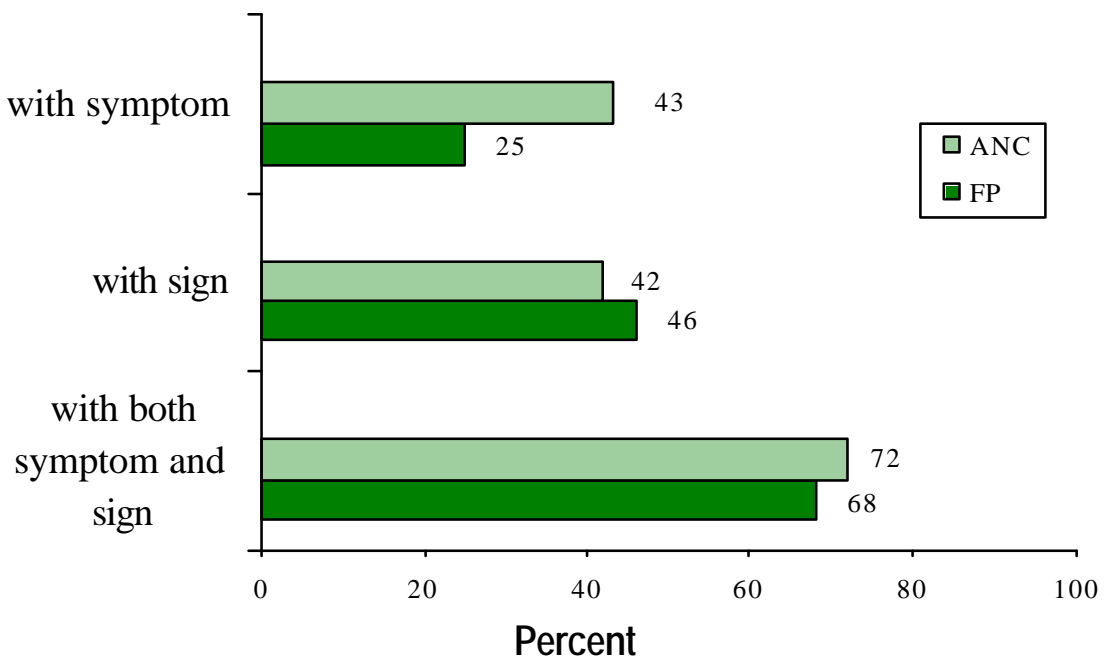

These findings suggest that clinic staff were not necessarily following the provided algorithms to diagnose and manage clients attending clinics for family planning and / or antenatal services. This finding may partially explain the big discrepancy between the small number of women syndromically diagnosed to have an STI and the large number of clients found to have an RTI on laboratory testing.

Thefindings also show that there is a discrepancy between reported symptoms of vaginal discharge and clinical findings. Fewer than one-half of women reporting vaginal discharge on history were found to have evidence of abnormal vaginal discharge on clinical examination. This in itself presents a decision-making problem for the clinical staff. Some of the syndromic algorithms available recommend that women be treated on the basis of symptoms alone while others recommend treatment only if the symptom is accompanied by clinical finding of an abnormal discharge. Since most of the available algorithms start with a symptom, clinical staff may not know what to do for thoseclients with no symptoms but have (not have) signs of abnormal vaginal discharge. This may be another reason for the smaller number of women for whom syndromic diagnosis was made in this study. 
A nother probable reason for the low number of women diagnosed syndromically is a function of the study; during the first debriefing meeting with providers, some indicated that because they knew women were getting tested, they chose to wait for lab results rather than using syndromic management. Although this was not the protocol for the study, it shows that somestill have more faith in lab diagnosis, and will rely on this if they havethe option.

How effective are current algorithms in identifying women with RTIs?

The effectiveness of using existing algorithms was assessed in this study by comparing syndromic diagnoses made by the clinic staff with laboratory test results. Data from this study show that using syndromic management will lead to some women being treated who do not have an RTI. However, the majority who were diagnosed to havethevaginal discharge syndrome, for example, did have an infection, though this was much more likely to be vaginitis than cervicitis. In fact, the positive predictivevalue - that is, the presence of infection in thosetreated syndromically for vaginitisis reasonable (either 61 or 70 percent), but is very low for cervicitis (8 or 11 percent). Using this approach to decide on treatment for vaginal discharge would have led to $36 \%$ and $29 \%$ of family planning and antenatal clients being treated for an RTI when in-fact they did nothave any infection. Asthese data show, syndromic approach to management of STIs does not lead to so much over-treatment of uninfected clients- a common belief and criticism of syndromic management. Although the positivepredictive values for any RTI and vaginitis werehigh, very few women with an infection were identified through this technique-that is, the sensitivity of using a diagnosis of vaginal dischargesyndrometo manage RTIs is extremely low (Table 9). The study showed that the majority of women with infection are missed when the vaginal dischargesyndromeis used - $95 \%$ and $82 \%$ of family planning and antenatal clients with laboratory evidence of an RTI were not diagnosed using syndromic approach.

\section{Table 9:}

Performance of vaginal discharge syndrome in identifying RTIS

\begin{tabular}{c|c|c|c} 
& Sensitivity & Specificity & Positive predictive value \\
\hline Any RTI FP & $5 \%$ & $79 \%$ & $48 \%$ \\
\hline ANC & $16 \%$ & $92 \%$ & $74 \%$ \\
\hline Vaginitis: FP & $5 \%$ & $97 \%$ & $61 \%$ \\
\hline ANC & $16 \%$ & $91 \%$ & $70 \%$ \\
\hline Cervicitis: FP & $6 \%$ & $96 \%$ & $11 \%$ \\
\hline ANC & $10 \%$ & $87 \%$ & $8 \%$
\end{tabular}


The current algorithms are symptom based- that is the starting point is the symptom that the client presents with. Once a client complains of a symptom, clinical assessment is undertaken and a decision taken whether to treat the client for that syndromeor not. Figure 7 pulls together some of theinformation on symptoms, signs and risk factors, showing the proportion of women with an RTI that has at least one symptom or clinical sign or risk factor. The data show that almost half of women who had a positive laboratory test for an RTI had no clinical signs or symptoms suggestive of an infection. This poses a significant problem for syndromic management to reach themajority of women with infection. Although roughly two-thirds of women with an RTI on laboratory testing did have at least one risk factor, this is still not a very useful way to identify cases since each individual risk factor had low prevalence and therefore is not useful as a predictor.

\section{Figure 7:}

Proportion of women with an RTI (lab diagnosis) with any symptom, clinical sign or risk factor

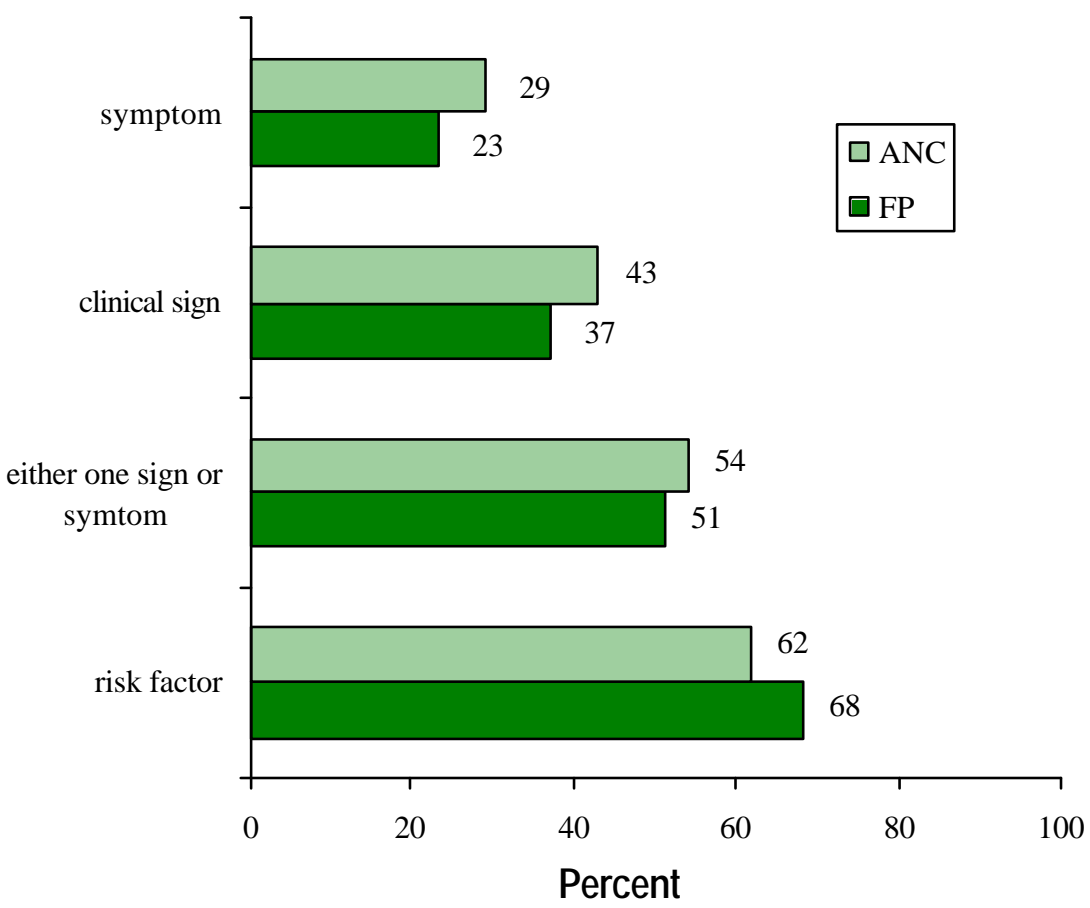

The effectiveness of the vaginal discharge symptom and/ or sign ${ }^{16}$ in identifying cervical infections was assessed using laboratory test results for the presence of gonorrhea and/ or chlamydia as the gold standard. Table 10 shows the sensitivity, specificity and positive predictive values when vaginal discharge symptom and/ or sign are used to diagnose cervical infections in women attending clinics for family planning and antenatal care services. In summary, vaginal discharge symptoms and/ or signs have poor sensitivity and positive predictive values but have a good specificity. This can be interpreted to mean that the vaginal discharge symptoms and/ or signs are very good in identifying women who do not have cervical infection but poor in identifying those with the infection. 
Table 10:

Effectiveness of the vaginal discharge symptom and/or sign in identifying clients with cervical infection

\begin{tabular}{l|c|c|c|c}
$\begin{array}{l}\text { Vaginal discharge } \\
\text { symptom andlor sign }\end{array}$ & Type of client & Sensitivity & Specificity & $\begin{array}{c}\text { Positive } \\
\text { predictive value }\end{array}$ \\
\hline Symptom alone & FP & 9 & 93 & 9 \\
\hline Sign alone & ANC & 19 & 84 & 11 \\
\hline & FP & 7 & 94 & 9 \\
\hline Both symptom and sign & FNC & 26 & 80 & 12 \\
\hline & FN & 4 & 98 & 16 \\
\hline
\end{tabular}

Do clients return for follow-up?

The clinical al gorithm currently in use in Kenya recommends that all women presenting with abnormal vaginal discharge be treated for vaginitis (trichomoniasis, candida and bacterial vaginosis) first and requested to return to the clinic one week later for review. At the one-week visit, a decision will be taken whether there has been clinical cure or the client needs treatment for cervical infection (gonorrhea and chlamydia). For this approach to effectively reach clients with cervicitis, the clients must return to the clinic for follow-up. Overall, 42 percent (381) of family planning clients and, 46 percent (371) of antenatal clients returned for their scheduled follow-up visits. It should benoted that this follow-up rate (over 40 percent) is higher than one would normally expect because women were more likely to return since they wanted to get their lab results. In addition, women were promised a reimbursement of their travel cost if they returned for the follow-up and that they would not have to pay any registration fee. Clients diagnosed to have an RTI using a syndromic approach were more likely to return for their follow-up visits. For example $57 \%$ of the 42 family planning clients for whom staff made a syndromic diagnosis ever came back to the clinic for review. Similarly, 51\% of the 121 antenatal clients with a syndromic diagnosis ever returned to the clinic for review. Given that this was a research project with other incentives mentioned above for the clients to come back, one would expect an even poorer return ratein normal clinic operations. Therefore, many clients with cervical infections may not receiveappropriate treatment despite having attended the clinics with suggestive symptoms.

\section{Does risk assessment make a difference?}

One way of improving on the effectiveness of the current clinical algorithms (flow charts) that has been proposed is the addition of risk assessment information to these tools. However, as shown earlier, most risk factors are not common among clients attending clinics for family planning and/ or antenatal 
care services. In addition there has been no general agreement on what risk factors to include in the risk assessment. One suggestion has been that these have to beadapted to local situations. In an attempt to identify locally relevant risk factors, information on several potential risk factors was obtained from all women recruited into thestudy. Using univariateand multivariateanalysis procedures ${ }^{17}$ a set of risk factors were identified for the family planning and antenatal clients separately. For the family planning clients, a model containing six risk factors (see Table 11) was fitted. This model was associated with a sensitivity of $5 \%$, specificity of $100 \%$ and positive predictive value of $60 \%$.

\section{Table 11:}

Risk Assessment model for cervicitis among family planning clients

\begin{tabular}{l|c|c|c|c} 
Variables in model & $\begin{array}{c}\text { Prevalence } \\
\text { of variable }\end{array}$ & $\begin{array}{c}\text { Crude } \\
\text { ODDS ratio }\end{array}$ & $\begin{array}{c}\text { Adjusted } \\
\text { ODDS Ratio }\end{array}$ & $\begin{array}{c}\text { Relative importance } \\
\text { of variable in model }\end{array}$ \\
\hline $\begin{array}{l}\text { History of lower abdominal } \\
\text { pain in client }\end{array}$ & 8.5 & 0.03 & 0.07 & 3 \\
\hline $\begin{array}{l}\text { History of purulent vaginal } \\
\text { discharge in client }\end{array}$ & 3.6 & 2.29 & 8.98 & 2 \\
\hline $\begin{array}{l}\text { Condom use during last } \\
\text { sexual intercourse }\end{array}$ & 7.2 & 0.58 & 0.20 & 2 \\
\hline $\begin{array}{l}\text { Frequent alcohol intake by } \\
\text { partner away from home }\end{array}$ & 42.4 & 1.58 & 1.74 & 1 \\
\hline $\begin{array}{l}\text { History of lower abdominal } \\
\text { pain in partner }\end{array}$ & 0.9 & 4.2 & 17.6 & 1 \\
\hline $\begin{array}{l}\text { History of STI treatment } \\
\text { in partner }\end{array}$ & 2.1 & 0.68 & 0.14 & 1 \\
\hline
\end{tabular}

To determine the relative importance of each of these variables in the model, we calculated the standardized coefficients for each of the variables and used the absolutevalues (corrected to thenearest whole number) to represent their relative importance. Using this approach, we found that a negative history of lower abdominal pain in the client was the most important variable. This was followed, in order of importance by a positivehistory of purulent vaginal discharge in the client, history of not using a condom during last sexual intercourse, history of no recent STI treatment in partner, frequent drinking by partner and a positive history of lower abdominal pain in the partner.

For the antenatal clients, the best model fitted included six variables (Table 12). A part from condom use during the last sexual intercourseand history of lower abdominal pain in partner, the rest of the variables were different from those identified in the model for family planning clients. The differences in socio- demographic characteristics and prevalence of infections between family planning and antenatal clients reported earlier may be responsible for the differences in themodels. This model was associated with a sensitivity of $7 \%$, specificity of $100 \%$ and positive predictive value of $63 \%$. 
Table 12:

Risk Assessment model for cervicitis among antenatal clients

\begin{tabular}{|c|c|c|c|c|}
\hline Variables in model & $\begin{array}{l}\text { Prevalence } \\
\text { of variable }\end{array}$ & $\begin{array}{l}\text { Crude } \\
\text { ODDS ratio }\end{array}$ & $\begin{array}{l}\text { Adjusted } \\
\text { ODDS Ratio }\end{array}$ & $\begin{array}{c}\text { Standardized } \\
\text { Coefficient }\end{array}$ \\
\hline Age of client (less than 19 years) & 20.7 & .99 & 2 & 1 \\
\hline $\begin{array}{l}\text { Condom use during last } \\
\text { sexual intercourse }\end{array}$ & 3.6 & .96 & .0003 & 4 \\
\hline $\begin{array}{l}\text { Frequent travel from home } \\
\text { by partner }\end{array}$ & 19.8 & 1.6 & 1.75 & 1 \\
\hline $\begin{array}{l}\text { History of blood stained } \\
\text { discharge in client }\end{array}$ & 1.0 & 5.9 & 8.30 & 1 \\
\hline $\begin{array}{l}\text { History of lower abdominal } \\
\text { pain in partner }\end{array}$ & 0.5 & 9.8 & 12.65 & 1 \\
\hline $\begin{array}{l}\text { History of pain on passing } \\
\text { urine in partner }\end{array}$ & 0.4 & 19.7 & 20.41 & 1 \\
\hline
\end{tabular}

Using the absolute values of the standardized coefficients for the variables in the model as described before, we found that not using a condom during the last sexual intercourse was the most important variable in the model. This was followed by age of the client (less than 19 years), history of frequent travel away from home by partner, history of blood stained vaginal dischargein client, history of lower abdominal pain in partner and history of pain on passing urine in partner in that order.

In summary, although these are the best risk assessment models that can be fitted from the data for predicting the presence of cervical infection among women attending clinics for family planning and antenatal services, they only identify a small number of clients with cervical infections. However, they have good specificity and positive predictive values.

Adding the presence of vaginal discharge symptom and/ or sign to the risk assessment models did not lead to any significant improvements in the ability of the clinical algorithms (flow charts) to predict the presence of cervical infection in women. The combined models for family planning clients were associated with poorer sensitivity, specificity and positive predictive values. The combined models for the antenatal clients did not have any effect at all on the ability of the algorithms to predict cervical infection

These data suggest that combining risk assessment and the clinical al gorithms that rely on the presence of vaginal discharge symptom and/ or sign may not lead to any significant improvements on the effectiveness of clinical algorithms (flow charts) in detecting cervical infections. 
Although risk assessment, or at least the risk factors that we measured in this study, do not appear to be helpful in improving case management, there are other potential benefits for incorporating risk assessment into services for ANC and FP clients. It can be an important aspect of counseling and generally of educating clients about their potential risk for STIs. It could certainly help in addressing one of the priority interventions recommended in therecent USAID integration guidelines: "counseling services to increase knowledge, perception of personal risk, behavior change, contraceptive method selection, etc." There is a need now to determine how to make sustained improvements to counseling and assess what kind of impact this has on clients' perceptions and behavior change. This study does provide evidence for the feasibility of adding risk assessment to counseling sessions. In addition, a study in Zimbabwe that included a time-motion study of providers showed that risk assessment took very little time, and so was not a significant burden on providers. (Marangwanda et al. 1999)

As part of the checklist, providers noted whether they counseled clients for various issues related to STIs and HIV/ AIDS. As figure 8shows, themajority of women did receive this counseling, according the provider reports. It is certainly possible with self-reporting to get an overestimate. However, what is notable is that the figures for dual contraception and for condom use are lower than for the other issues. Based on the high prevalence of RTIs and the low ever use of condoms among clients in the study, it seems clear that counseling on condoms, including their use with other methods, is an area that still needs improvement. Although no baselineinformation was collected immediately prior to the introduction of thechecklist, an earlier study (Kariba et al.) had found that clients attending the Nakuru Municipal Council clinics for MCH/ FP services rarely received any STI/ HIV IEC and counseling. One reason given at the time was lack of a standardized checklist to guide and keep reminding the providers of the need to provide this service to clients. This study, therefore, demonstrates that when such a checklist is made available most clients get counseled about STIs and HIV/ AIDS.

\section{Figure 8:}

Counseling on STI related issues among FP and MCH clients

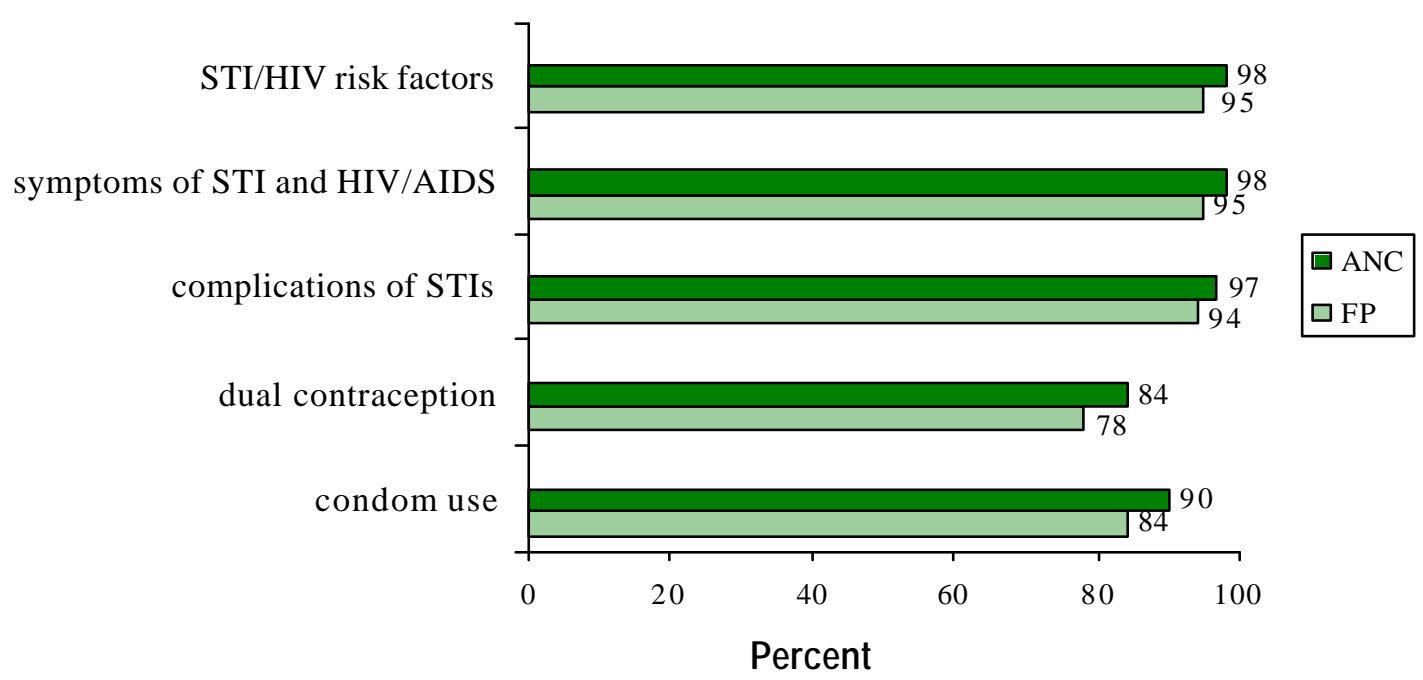


It is essential that integrated programs look at effective ways to have partners treated. Otherwise, women are at a significant risk of being reinfected even if they do actually receive treatment and are cured of their infection. However, there are a number of problems with partner notification in syndromic management. First of all, with syndromic management, some women without infection are actually diagnosed. Having them notify partners then that they should get treatment can lead to various negative repercussions. In addition, syndromic management does not give a specific diagnosis but instead identifies a woman as having a syndrome, which can be caused by various infections, only, some of which aresexually transmitted. In this project, the most common RTIs among the ANC and FP clients were bacterial vaginosis and candidiasis, both of which arenot sexually transmitted and do not necessarily requirepartner notification. It is important to keep in mind that one of the principles of partner notification is to "do no harm". In a discussion on partner notification in the AIDSCA P handbook on the control of STDs, theauthors point out that " $V$ aginal discharge is less specific for the presence of an STD. The decision to treat male partners of women with vaginal discharge should be made based on the overall preval ence of STD in the community and the availability of laboratory diagnosis." ${ }^{18}$

\section{Provider and client perspectives}

As described earlier, providers used a checklist to collect information from each client. This checklist included medical history, obstetric and gynecological history, clinical information, counseling issues and risk assessment questions. The amount of information collected was more extensive than what was done in regular practice in the clinic, so we asked both providers and clients how they felt about this process and about the project in general. In particular, we focused on perceptions of the pelvic and speculum examination and the risk assessment questions. All 18 providers who participated in the study were interviewed. In addition, 195 clients wereinterviewed, including 101 antenatal and 94 family planning clients. The researchers based at the clinics conducted the interviews with all clients who consented over a one-week period.

\section{General comments}

Many providers felt that the checklist was initially difficult to implement. Of the 18 providers involved in the study, 13 felt it was either somewhat difficult (9) or very difficult (4). Mostly, they emphasized that it took a lot of time. Some also felt that a few of the questions in the risk assessment portion were too difficult or too personal to ask. However, providers said that after using the checklist for a couple of months, their perceptions changed. Only 2 of the 18 felt that it was somewhat difficult, while 16 said it was not difficult to implement (figure 9). 


\section{Figure 9:}

Change in provider attitudes towards implementing the checklist

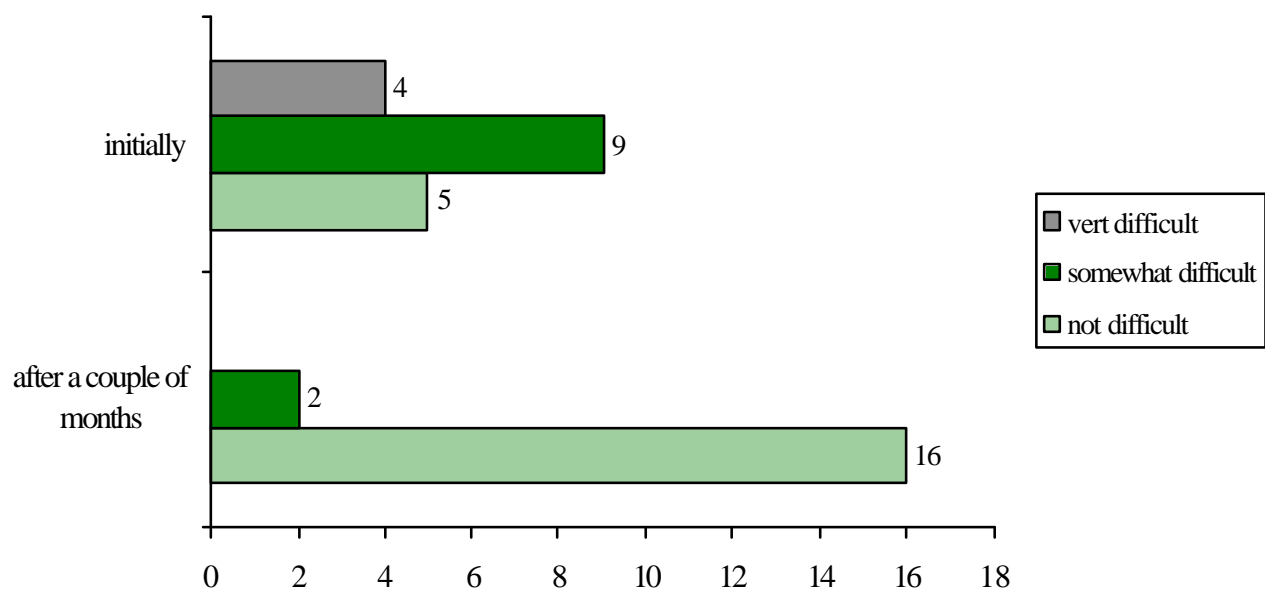

Overall, providers felt that the checklist was useful. Most (14) said it was very useful, while the remainder (4) felt that it was somewhat useful. As one provider explained, “we were able to detect things wew ouldn't have detected, e.g. A N C mothers have infections, which we normally overlook if the client doesn't mention it." Another said that "after completing the checklist you know what type of partner she has and also during the checklist you counsel the woman on various ways to handle situations, i.e. if her partner is cheating on her." Almost all (17) would like to continue using a checklist for managing clients, either the same one (6) or a modified version (11). Most changes that providers proposed had to do with shortening the checklist to makeit more manageable as part of their regular practice. They

Client comments regarding integrated services

"This is a blessing, because of these exams. So many women will be ne fit and this should continue."

"These services are very helpfulfor women because if the husband is unfaithful and infects her with a disease, she will be able to get treatment and both will receive counseling on $S \mathcal{T} I s$ and ways to avoid the m, especially the man."

"I would recommend that we women be getting these kind of services at least once a year. I was very happy and satisfied." felt that there were sections that were unnecessary and just created extra work and wasted time.

Providers wereal so asked about general issues around integration of services. The main problems that they had encountered included the following: staff shortages, time taken to complete checklist, someclients could not pay for treatment if an STI was identified, contact tracing, and lack of equipment. The solutions that they proposed included adding more staff, providing drugs free of charge and improving counseling to help improve contact tracing.

Clients werevery enthusiastic about the services that they received. The comments shown in box show some of their feelings. 
Almost all (99.5 percent) would recommend the clinic to a friend. When asked why, about half (49 percent) said because they liked the services, 23 percent mentioned that they would like her to benefit as well, 21 percent cited the importance of the exams and 17 percent referred to that fact that the staff were pleasant and good-hearted. Of those who had not come to a Municipal Council clinic before, roughly one-third (32 percent) had themselves been recommended by a friend. Of thewomen who had received services previously from the clinic, they felt that the services were very different and that they were happy and pleased about these differences. In particular, they liked the fact that they would find out if they were sick. Antenatal clients were also happy to find out if their baby was healthy. When clients were asked what they particularly disliked about the services, most (87 percent) said they liked it all. Of the remaining 13 percent, the most common responses were that they waited too long (five percent) or that they disliked the speculum exam (five percent).

Weasked providers if their participation in the project has influenced the way they do their work and relate to clients, and most (16) said that it did. In particular they focused on the improvements in their interactions with clients. They felt that through spending

"The nature of this study

has meant that one is

spending more time than we

usually do with a client..T The

fact that you've dealt so

closely and personally with a

client motivates you to

follow her up and see that

she gets treatment if it's

necessary and that she's

okay... One tries to do one's

best and you give e ach

client time and make sure

you've done a thorough job.

The reward has been the

client's appreciation. They

have told us we are doing an

excellent job-one that's

very helpful to women." provider more time with clients they were able to develop better rapport, the relationships became closer and the trust greater. In addition, it enabled providers to understand clients better. In the words of one provider, "I can relate very nicely with clients because they feel that the provider is interested in their health and we are ready to help them in case of any problem." In the quote (shown in box), a provider describes how the relations with clients changed and how this in turn acted as a motivation in her work:

However, one provider pointed out problems with the way they had been offering services during the project. She felt that the services offered actually deterred singlewomen from coming. As she explained, "the single ones have kept away because they know what it is we're looking for (i.e. STIs) and they don't want these tests."

\section{Clinical Procedures}

Providers were asked about the various procedures they performed as part of thechecklist, including thegeneral exam, breast exam, pelvic exam and clinical history. The vast majority felt completely comfortable with performing these procedures, with the exception of the pelvic exam, for which one-third of the providers indicated that they were only partly comfortable. They explained 
that this was due to thefact that they had not been typically doing this and so they felt out of practice. Almost all felt that the procedures were very useful in terms of managing clients. As one provider explained, "all these procedures are very useful as they act as a way to determine a client's condition even before the specimen taking. They help one rule out certain conditions as well as determining any problems a client may be having right from the beginning."

Providers did feel that it was more difficult to implement portions of the checklist with antenatal clients. In particular, the digital exam posed a problem with these clients, especially checking for cervical excitation and the position of the uterus. However, they did feel that it was important to continue performing a speculum exam for both FP and antenatal clients in order to sustain the quality of care that they had been providing.

While the majority (76 percent) of clients said they were completely comfortablewith the speculum exam, 21 percent wereonly partly comfortable and 5 women ( 3 percent) were not at all comfortable. Many of those who were partly comfortable said that they were initially scared, as some had never had "that metal thing" inserted in them before, but it was not as bad as they had expected. The following quotes elaborate on this:

- "at first I was scared, but sister explained everything and I was reassured"

- in the beginning I was tense, but actually the speculum is not painful. I was just scared for nothing."

- "first I was scared of the speculum, but I found it is not painful only uncomfortable"

The following quote from a client shows the difference in perception of the examination when clients are not properly counseled beforehand: "I was slightly scared of having the speculum inserted. I thought that the doctor was going to leave it inside and also I didn't understand why it was being inserted." A nother woman explained her discomfort with thetaking of specimens: "I've never had a blood or urine sample taken before so I felt slightly embarrassed giving a urine sampleand scared of having blood removed. It's not that I disliked it, it was just a bit embarrassing."

"I particularly

liked the exam. gouknow us mothers never get time to be examine d. Now that it is done at this time it is much better and very convenient."

Client.
When asked about what they particularly liked about theservices that they had received, the majority (71 percent) specifically mentioned theexamination and the tests done to find out whether or not they were sick.

Not only did women mention the exams as an aspect of services that they particularly liked, but they al so mentioned the exams as a key reason that they would recommend the services to a friend. This was referred to by 21 percent of women interviewed. They felt these exams were important and thorough and would detect any infection the woman might have. 
The risk assessment portion of the checklist included 23 questions about the client's behavior as well as her partner's behavior (see appendix 1). Questions included issues such as number of sexual partners, drinking patterns and whether the client or her partner's work takes them away from home. There is a widespread assumption that neither providers nor clients feel comfortable with these types of questions, in particular the questions regarding sexual behavior. Wefound that this was generally not true. Although somequestions were viewed as problematic, both providers and clients felt fairly comfortable about asking or being asked these questions, and also saw the usefulness of doing so. One client explained that " the questions asked are good- they make one think," while another explained that "they are informative." One woman said she particularly liked those questions about sexual behavior because " they make me aware of possible STIs and how to avoid them."

A mong the 18 providers, only one indicated that shewas not at all comfortable with asking thequestions. The rest weresplit between feeling partly comfortable (9) and completely comfortable (8) with the questions. A few questions were seen as repetitive or unnecessary. The one question that a large number of providers felt was a problem was the question "When was the last time you had sexual intercourse". They felt that this was too personal and that it "goes against our cultural beliefs to ask so it tends to make clients uncomfortable." Two providers thought that the checklist would be better without the risk assessment portion.

Almost all (99.5 percent) of the clients interviewed said that they were completely comfortablewith being asked about their behavior, while 98 percent were completely comfortable with being asked questions about their partner's behavior. When women were asked what they particularly liked about the services they had received, 11 percent mentioned the questions that they were asked. It is certainly likely that there was some courtesy bias in how clients responded to these questions. Providers indicated that they felt that clients sometimes did not answer truthfully during the risk assessment questions because they were uncomfortable with being asked sensitive questions. 


\section{Concluding Observations and Recommendations}

These findings support some of the guidel ines put forth in a recent document from USAID, Integration of Family Planning/M CH with HIV/STD Prevention, Programmatic Technical Guidance: Priority for Primary Prevention with a Focus on H igh Transmitters (December 1998). The authors summarize a number of weaknesses of integrated programs, including an overemphasis on theclinical management of STDs, the ineffectiveness of the syndromic algorithm for vaginal discharge, and inadequate support for primary prevention of sexual transmission of HIV and other STDs, especially for condom promotion and behavior change intervention. Based on these weaknesses and successes of various other projects, they recommend a number of activities, including the following:

- behavior change communication to reduce unsafe, unprotected sex

- aggressive condom promotion both in clinics and non-clinical settings

- counseling services to increase knowledge, perception of personal risk, behavior change, contraceptive method selection, etc.

In addition to supporting the above, the findings from this study al so provide evidence for the feasibility of improving counseling and other primary prevention activities. The findings also stress theimportance of the community element in improving efforts at addressing the problems of HIV/ AIDS and STDs. The authors of the USAID report refer to this in stating that "interventions for the general population support a social norm for action against STD s that is necessary for the overall effort." The problems of STIs and HIV/ AIDS will not be changed solely by work in the clinics, and it is clear that there must be continuing efforts to help changecommunity norms regarding sexual behavior, condom use, health seeking behavior and partner communication. It is only in this way that there will be true and sustained change.

Two dissemination workshops were held: the first in Nakuru with over 50 participants on February 2, 1999 and the second two days later in Nairobi with over 40 participants. The meeting in Nakuru included representatives from the Provincial Medical Officer's office, the Nakuru Municipal Council, including the nurses from the clinics who had been involved in the study, the MOH's Provincial General Hospital and other district and provincial level personnel.

The Provincial Clinical Officer set the tone of the meeting in Nakuru with the following words: "research is meant to improve our work so we can do things effectively." This led to extensive discussion and suggestions on the meaning of the findings and the implications for programs and policy. The 
recommendations from Nakuru were then incorporated into the Nairobi dissemination and became part of the lively discussion that followed the presentation of findings. The following were the key recommendations.

- Focus on prevention; given the problems associated with using the syndromic approach to identify and manage RTIs among women attending MCH/ FP clinics, we should emphasize taking a public health approach where we emphasize preventive approaches that have been shown to be cost-effective compared with treatment. A participant at one of the workshops summed the discussions thus;

"While we continue

to de bate syndromic

manage me nt, we can

focus on $\mathcal{T E C}$,

condom promotion,

counse ling and

raising awareness $a b$ out $\mathcal{S} \mathcal{T} I s$
- Improve on STI/HIV IEC; thelargediscrepancy between reported symptoms and signs found during clinical examination might bea reflection of clients' poor knowledge of the symptoms associated with theseinfections. Therefore there is a need to improve skills of providers and to encourage them to undertake systemic STI/ HIV IEC for clients in order to improve on clients' knowledge of STI/ HIV related symptoms and signs.

- Emphasis on clinical examinations; Data from the study showed major discrepancies between reported symptoms suggestive of RTIs and clinical findings. Clinical examinations identified more women with RTI related signs compared with reported symptoms. In addition, clinic staff were comfortable conducting the examinations and the clients appreciated being examined. Therefore, staff need to be encouraged and enabled to undertake clinical examinations for antenatal and family planning clients routinely.

- Encourage the use of integrated and standardized checklists in the provision of family planning, antenatal care and STI/HIV services. Data from the study showed that the checklist enabled more clients with symptoms and signs suggestive of STIs to beidentified and the vast majority of clients received STI/ HIV counseling.

- R eview our partner notification strategies and improve community understanding that not all infections are sexually transmitted given that most of the infections among women attending MCH/FP clinics are not sexually transmitted; as one provider explained, "we need to have a language to explain the infection... most RTIs are not STIs. The moment we label it an STI, we break up the family rather than unite the family."

- Review treatment guidelines to emphasize effective treatment of vaginal infections, which have a high prevalence among this population; though there has been a strong focus on cervical infections, recent evidence indicates the importance of treating bacterial vaginosis and trichomoniasis both of which are much more common than gonorrhea and/ or chlamydia and have a high potential for serious health impacts.

- Continue using syndromic management in Nakuru to manageclients presenting with symptoms in spite of its problems, until there is something better; the following comments reflect this opinion from participants in Nakuru: "What alternative is there?"; "For some time we may have to do without labs as there are no funds to support them"; " meanwhile, we need to do something for those clients with symptoms." 
AIDS epidemic update: December 1998. UNAIDS Joint United Nations Program on HIV/AIDS and the World Health Organization.

An Overview of Selected Curable Sexually Transmitted Diseases. WHO Office of HIV/AIDS and Sexually Transmitted Diseases.

http://www.who.int/asd/akagmer.htm

AIDS in Kenya: Background, Projections, Impact and Interventions.

Edited by TM Okeyo,

GM Baltazar, J Stover, A Johnston. Fourth Edition, National AIDS and STDs Control Program (NASCOP), 1998.

Grosskurth, Heiner et al. "Impact of improved treatment of sexually transmitted diseases on HIV infection in rural Tanzania: randomized controlled trial." The Lancet. Vol. 346. August 26, 1995.

Action for the $21^{\text {st }}$ Century Reproductive Health \& Rights for All. Summary report of recommended actions on reproductive health and rights of the Cairo ICPD Program of action, September 1994. Prepared by Maria Jose Alcala, Family Care International. 1994. New York. Health Worker Training in Sexually Transmitted Infections: Facilitator Notes. Strengthening STD/AIDS Control in Kenya Project. University of Nairobi and University of Manitoba. March 1996.

Maggwa, Baker Ndugga and Ian Askew. Integrating STI/HIV Management Strategies into Existing MCH/FP Programs: Lessons from Case Studies in East and Southern Africa. The Population Council. Nairobi, Kenya. July 1997

Welsh, M., P. Feldblum and S. Chen. "Sexually Transmitted Disease Risk Assessment Used Among Low-Risk Populations in East/Central Africa: A Review." East African Medical Journal. Vol. 74 No. 12. December 1997.

Twahir A., Maggwa BN and Ian Askew. Integration of STI and HIV/AIDS Services with MCH-FP Services: A Case Study of the Mkomani Clinic Society in Mombasa, Kenya. Africa OR/TA Project II, Population Council, Nairobi, Kenya. 1996; and Kariba WJ., Kariuki KB and Maggwa BN. Integration of STI and HIV/AIDS with MCH-FP Services: A Case Study of the Nakuru Municipal Council's Project on Strengthening STD/AIDS Control. Africa OR/TA Project II, Population Council, Nairobi, Kenya. 1997

Mukaire J., Kalikwani F., Maggwa BN and Kisubi W. Integration of STI and HIV/AIDS Services with MCH-FP Services: A Case Study of the Busoga Diocese Family Life Education Program, Uganda. Africa OR/TA Project II, Population Council, Nairobi, Kenya. 1997.

Baakile B., Maribe SJ., Maggwa BN and Miller RA. A Situation Analysis of the Maternal \& Child Health/Family Planning (MCH/FP) Program in Botswana. Africa OR/TA Project II, Population Council, Nairobi, Kenya. 1996;

Maggwa BN and Askew I. op. cit. 1997. 
Dallabetta, Gina A, Antonio C Gerbase and King K Holmes. "Problems, solutions, and challenges in syndromic management of sexually transmitted diseases." Sexually Transmitted Infections. June 1998. Vol. 74, Supplement I.

Kenya Demographic and Health Survey 1998, Preliminary Report. Macro International Inc. Calverton, Maryland. September 1998.

Toomey, Kathleen E., Ahmed S. Latif and Richard C. Steen. "Partner Management" in Control of Sexually Transmitted Diseases: A Handbook for the Design and Management of Programs, edited by Gina Dallabetta, Marie Laga and Peter Lamptey. AIDSCAP/ Family Health International. 
A vaginal discharge symptom was said to be present if a client complained of the presence of yellow, or blood stained or foul smelling or an increase in the vaginal discharge. The vaginal discharge sign was said to be present if on clinical examination the client was found to have a white curd-like or greenish or yellow vaginal discharge or curd-like discharge in the vagina or a discharge from the cervix.

Model selection using Multivariate Logistic Regression: variables were entered into the model if they were observed to be significant at $10 \%$ in the univariate analysis for each specific section, i.e. history, clinical exam and risk assessment. They were subjected to a stepwise multiple logistic procedure using the backward selection procedure in order to control for confounding factors. 
PAGE

\section{Executive Summary}

Introduction

Study Design

Summary and Key Findings

\section{Study Design and Data Collection}

Methodology and Objectives $\quad 6$

Field Work and Data Collection 8

$\begin{array}{ll}\text { Laboratory Procedures } & 10\end{array}$

Data Entry and Analysis $\quad 11$

\section{Findings}

Characteristics of Sample 13

$\begin{array}{ll}\text { Symptoms } & 17\end{array}$

Clinical Signs 18

Risk Factor Information 19

Effectiveness of Syndromic Management 21

$\begin{array}{ll}\text { Provider and client perspectives } & 29\end{array}$

Concluding Observations and Recommendations

\section{Reference and Notes}

Appendix 


\section{REPRODUCTIVE HEALTH ASSESMENT AND MANAGEMENT FORM FOR THE NAKURU MUNICIPAL COUNCIL STI STUDYI FP FORM \\ ${ }^{*}$ Informed Consent obtained (circle one): yes no}

\section{Clinic and Personal Information}

attach sticker

\begin{tabular}{|l|l|l|l|}
\hline Health Facility name & Marital status & YES & NO \\
\hline Client No. & Cohabiting & & \\
\hline Study No. & Married (Polygamous) & & \\
\hline Time consultation began: & Married (Monogamous) & & \\
\hline Date: Day Month Year & Divorced/Separated & & \\
\hline Client's Name Day Month Year & Widowed & & \\
\hline Date of birth Single (never married) & & \\
\hline Education (Grade completed ) & Grade & Age at first marriage: & \\
\hline \multicolumn{2}{|l|}{ Primary } & $\begin{array}{l}\text { Contact address (Ask for physical address: } \\
\text { '"how do I find you?') }\end{array}$ \\
\hline Secondary & box: \\
\hline Tertiary & village/estate: \\
\hline Occupation of client & sublocation: \\
\hline Occupation of spouse/partner & other info: \\
\hline Husband/Father's name & Religion: \\
\hline
\end{tabular}

2. Reason for clinic visit, Obstetric and Gynaecologic History

\begin{tabular}{|c|l|l|l|l|l|}
\hline Reasons for visiting the clinic today & YES & NO & $\begin{array}{l}\text { Gynaecologic History (Does } \\
\text { client currently have ---- ? }\end{array}$ & YES & NO \\
\hline New family planning client & & & Lower abdominal pain (PID) & & \\
\hline Restarting Family Planning & & & Yellow discharge & & \\
\hline Annual examination & & & Blood stained discharge & & \\
\hline Re-supply / revisit & & & Foul smelling discharge & & \\
\hline Problem with method & & & Increased amount of discharge & & \\
\hline STD treatment & & & Post coital bleeding & & \\
\hline Infertility & & & Pain during sexual intercourse & & \\
\hline Date of last visit: & & & Pain on passing urine & & \\
\hline
\end{tabular}




\begin{tabular}{|l|l|l|l|l|}
\hline Obstetric History & Genital ulcers/wounds/sores & & \\
\hline No. of total pregnancies & & Painful swellings in the groin & & \\
\hline No. of living children & & Warts in the genital area & & \\
\hline Ages of children & & Bleeding between periods & & \\
\hline No. of stillbirths & & Dysmenorrhoea & & \\
\hline No. of neonatal deaths & & & \\
\hline Date last pregnancy ended: Day Month Yr. & LMP: Day Month Year \\
\hline
\end{tabular}




\begin{tabular}{|c|c|c|c|c|c|c|}
\hline Out come of last pregnancy & YES & NC & \multicolumn{4}{|l|}{ Age at menarche: } \\
\hline \multicolumn{7}{|l|}{ Live birth } \\
\hline Stillbirth & & & \multicolumn{4}{|l|}{ Reproductive Intentions } \\
\hline Abortion & & & \multicolumn{4}{|l|}{ No. of desired children: } \\
\hline Neonatal death & & & \multicolumn{4}{|l|}{ Timing of next child: } \\
\hline \multicolumn{7}{|l|}{ Is client on menses? } \\
\hline \multicolumn{7}{|l|}{ Cycle length (No. of days): } \\
\hline \multicolumn{7}{|l|}{ No. of bleeding days: } \\
\hline \multicolumn{3}{|l|}{ Flow: regular/irregular: } & \multicolumn{4}{|c|}{ Is client currently breast-feeding? } \\
\hline \multicolumn{7}{|c|}{ 3. General Medical and Contraceptive History } \\
\hline $\begin{array}{l}\text { Medical history (Has client ever had } \\
\text { or currently have ----- ?) }\end{array}$ & YES & NO & Contraceptive use history & $\begin{array}{l}\text { Ever } \\
\text { Use }\end{array}$ & & $\begin{array}{l}\text { irrent } \\
\text { Use }\end{array}$ \\
\hline Varicosis & & & Combined pill & & & \\
\hline Jaundice & & & Progesterone only pill & & & \\
\hline Renal disease & & & Male condom & & & \\
\hline Hypertension & & & Spermicide & & & \\
\hline STD & & & IUD/Loop & & & \\
\hline Diabetes & & & Injectables & & & \\
\hline Epilepsy & & & Implants & & & \\
\hline Tuberculosis & & & Female Sterilisation & & & \\
\hline Goitre & & & Male Sterilisation & & & \\
\hline Severe weight loss & & & Traditional Methods & & & \\
\hline Severe weight gain & & & LAM & & & \\
\hline Headaches & & & Natural FP & & & \\
\hline Thrombosis & & & Female Condom & & & \\
\hline Allergy to medicines (e.g., Penicillin) & & & & YES & NO & \\
\hline Toxaemia of pregnancy & & & Are you on any medication? & & & \\
\hline Asthma & & & Does client smoke? & & & \\
\hline \multicolumn{7}{|c|}{ 4. Clinical examinations, Diagnosis and Treatment } \\
\hline \multicolumn{3}{|l|}{ General examination. } & \multicolumn{2}{|l|}{$\begin{array}{l}\text { Speculum examination [TAKE } \\
\text { SPECIMENS AT THIS TIME] }\end{array}$} & YES & NO \\
\hline Blood Pressure & & & \multicolumn{2}{|l|}{ Warts on vagina wall } & & \\
\hline Weight & & & \multicolumn{2}{|l|}{ Curdy discharge in vagina } & & \\
\hline Does the Client Have --------- ? & YES & NO & \multicolumn{2}{|l|}{ Cervical warts/polyps } & & \\
\hline Hair loss or colour change & & & \multicolumn{2}{|l|}{ Discharge from cervix Os } & & \\
\hline Jaundice & & & \multicolumn{2}{|l|}{ Cervical erosion/ulcers } & & \\
\hline Anaemia & & & \multicolumn{2}{|l|}{ Digital examination/Bimanual } & & \\
\hline Ulcers/sores in mouth & & & \multicolumn{2}{|l|}{ Cervical excitation } & & \\
\hline Enlarged thyroid gland & & & Retroverted uterus & & & \\
\hline Skin rashes & & & Anteverted uterus & & & \\
\hline Enlarged lymph-nodes & & & Enlarged uterine size & & & \\
\hline Enlarged liver & & & Tenderness in adenexia & & & \\
\hline Breast Exam. Does client have -? & YES & NO & Ovarian masses & & & \\
\hline Dimples in the skin & & & Syndromic Diagnosis & & & \\
\hline Breast masses/lumps & & & Vaginal Discharge & & & \\
\hline Discharge from the nipple & & & Genital ulcer & & & \\
\hline Ulcers/sores on breast & & & Lower abdominal pain & & & \\
\hline Enlarged axilla nodes & & & Bubo (swelling in the groin) & & & \\
\hline Pelvic exam. Does client have -? & YES & NO & Warts & & & \\
\hline Inspection (vulva/buttocks/groin) & & & Treatment given for syndrome & & & \\
\hline
\end{tabular}




\begin{tabular}{|l|l|l|l|}
\cline { 3 - 4 } & & & 1. \\
\hline Rashes/Vesicles & & & 2. \\
\hline Ulcers/wounds/sores & & & 3. \\
\hline Warts & & & 4. \\
\hline Clear discharge & & & $\begin{array}{l}\text { Family Planning method given (for pill, note \# of } \\
\text { cycles given; for condom, \# of condoms) }\end{array}$ \\
\hline White/curdy discharge & & & 1. \\
\hline Greenish discharge & & & 2. \\
\hline Yellow discharge & & & If none, reason: \\
\hline & & Return Date: Day Month Year \\
\hline
\end{tabular}

\section{Counselling}

\begin{tabular}{|l|l|l||l|l|l|}
\hline $\begin{array}{c}\text { Counselling for STIs and } \\
\text { HIV/AIDS } \\
\text { (NOTE: for all clients) }\end{array}$ & YES & NO & $\begin{array}{c}\text { Information given to Clients with } \\
\text { STIs (NOTE: only for clients } \\
\text { who are given treatment) }\end{array}$ & YES & NO \\
\hline STI/HIV risk factors & & & Importance of completing therapy & & \\
\hline Modes of transmission & & & $\begin{array}{l}\text { Importance of protecting partners } \\
\text { during therapy }\end{array}$ & & \\
\hline Symptoms of STD and HIV/AIDS & & & $\begin{array}{l}\text { How to protect partners from } \\
\text { infection }\end{array}$ & & \\
\hline Complications of STDs & & & Condom use & & \\
\hline Dual Contraception & & & Need to refer partner for therapy & & \\
\hline Condom use & & & Need to return for check up & & \\
\hline
\end{tabular}

\section{Laboratory tests}

\begin{tabular}{|l|l|l|l|l|l|}
\hline $\begin{array}{l}\text { Specimens taken for lab tests } \\
\text { (check if taken) }\end{array}$ & YES & NO & $\begin{array}{l}\text { Laboratory Test Results } \\
\text { (to be completed later) }\end{array}$ & Positive & Negative \\
\hline urine for Gonorrhea/ Chlamydia & & & LCR for Gonorrhea & & \\
\hline & & & LCR for Chlamydia & & \\
\hline HVS for Candidiasis & & & Candida & & \\
\hline HVS for Bacterial Vaginosis & & & Bacterial Vaginosis & & \\
\hline HVS for Trichomonas (in-pouch) & & & in pouch test & & \\
\hline Urine for pregnancy test & & & Pregnancy test & & \\
\hline
\end{tabular}

\section{Follow-up}


[NOTE: Follow-up information to be completed when client returns for follow up appointment]

\begin{tabular}{|l|l|l|l|l|l|}
\hline Follow-up Visit & YES & NO & Contact tracing & YES & NO \\
\hline Date returned: Day Month Year & Contact treated & & \\
\hline Returned on scheduled date & & & & & \\
\hline Returned after due date & & & & & \\
\hline Returned following home visit & & & & & \\
\hline Clinically cured if had STI & & & & & \\
\hline Treatment changed to if not cured & & & & & \\
\hline 1. & & & & \\
\hline 2. & & & & \\
\hline 3. & & & & \\
\hline Client referred elsewhere & & & & \\
\hline
\end{tabular}




\section{STD/HIV RISK ASSESSMENT CHECK LIST}

\begin{tabular}{|c|c|c|c|}
\hline \multirow{2}{*}{$\begin{array}{l}\text { Questions } \\
\text { 1. Does your employment /major source of income activity involve travelling and } \\
\text { staying away from home frequently? } \\
\text { (Ile kazi ambayo unafanya ama ile njia ambayo inakupatia mapato inakubidi usafiri } \\
\text { na ukae mbali na nyumbani mara nyingi?) }\end{array}$} & YES & NO & DK \\
\hline & & & \\
\hline \multicolumn{4}{|l|}{$\begin{array}{l}\text { 2. Have you stayed away from home for a month or more in the past three months? } \\
\text { (Kwa miezi mitatu iliopita, umewahi kukaa mbali na nyumbani kwa mwezi mmoja } \\
\text { ama zaidi?) }\end{array}$} \\
\hline \multicolumn{4}{|l|}{$\begin{array}{l}\text { 3. Have you stayed away from home in the past four weeks? (Katika mda wa wiki } \\
\text { nne zilizopita, umewahi kukaa mbali na nyumbani?) }\end{array}$} \\
\hline \multicolumn{4}{|l|}{$\begin{array}{l}\text { 4. Do you have a regular sex partner? By regular sex partner I mean someone you } \\
\text { had a relationship for at least one year [for married women, other than spouse] } \\
\text { (Uko na rafiki wa kila mara ambaye mnaonana kimwili?) }\end{array}$} \\
\hline $\begin{array}{l}\text { 5. For how long have you known your spouse (regular } \\
\text { partner)? (Umemjua kwa mda gani?) }\end{array}$ & & & \\
\hline \multicolumn{4}{|l|}{$\begin{array}{l}\text { 6. Does your spouse's (regular partner's) employment /major source of income } \\
\text { activity involve travelling and staying away from home frequently? (Kazi ambayo } \\
\text { huyo mpenzi mmeo wako anayofanya, ama njia ile ambayo inampatia mapato, } \\
\text { inambidi asafiri na akae mbali na nyumbani mara nyingi?) }\end{array}$} \\
\hline \multicolumn{4}{|l|}{$\begin{array}{l}\text { 7. Has your spouse (regular sex partner) stayed away from home for more than a } \\
\text { month in the past three months? (Katika mda wa miezi tatu iliyopita huyo mpenzi } \\
\text { mmeo wako amewahi kukaa mbali na nyumbani kwa mda wa mwezi moja au zaidi?) }\end{array}$} \\
\hline \multicolumn{4}{|l|}{$\begin{array}{l}\text { 8. Has your spouse (regular partner) stayed away from your home in the past four } \\
\text { weeks? (Katika mda wa wiki nne zilizopita, huyo mpenzi mmeo wako amewahi } \\
\text { kukaa mbali na nyumbani?) }\end{array}$} \\
\hline \multicolumn{4}{|l|}{$\begin{array}{l}\text { 9. Does your spouse (regular partner) go out to drink alcohol at least once a week? } \\
\text { (Mpenzi mmeo wako huenda nje kunyua pombe angalao mara moja kwa wiki?) }\end{array}$} \\
\hline \multicolumn{4}{|l|}{$\begin{array}{l}\text { 10. Do you go out to drink alcohol at least once a week? (Wewe mwenyewe huenda } \\
\text { nje kunyua pombe angalao mara moja kwa wiki?) }\end{array}$} \\
\hline \multicolumn{4}{|l|}{$\begin{array}{l}\text { 11. Some men have sex with more than one woman. Do you think that your spouse } \\
\text { (partner) has sex with other women? (Wanaume wengine wanaonana kimwili na } \\
\text { wanawake wengine. Unadhani mpenzi wako/mmeo hufanya hivyo?) }\end{array}$} \\
\hline \multicolumn{4}{|l|}{$\begin{array}{l}\text { 12. Do you think that you are at an increased risk of getting an STD infection? } \\
\text { (Unadhani unaweza kuambukizwa ugonjwa wa zinaa?) }\end{array}$} \\
\hline \multicolumn{4}{|c|}{$\begin{array}{l}\text { 12a.If yes to Q12. Why do you think that you are at increased risk?(Kwa nini unadhani unaweza } \\
\text { kuambukizwa) }\end{array}$} \\
\hline \multicolumn{4}{|l|}{$\begin{array}{l}\text { 13. Do you think that you are at increased risk of getting HIV infection? (Unadhani } \\
\text { uko hatarini kwambukizwa na Ukimwi?) }\end{array}$} \\
\hline \multicolumn{4}{|c|}{$\begin{array}{l}\text { 13a.If yes to Q.13. Why do you think that you are at increased risk? (Kwa nini unadhani unaweza } \\
\text { kuambukizwa?) }\end{array}$} \\
\hline \multicolumn{4}{|l|}{$\begin{array}{l}\text { 14. Do you think that you might be having an STD infection currently? (Unadhani } \\
\text { waweza kuwa na ugonjwa wa zinaa wakati huu?) }\end{array}$} \\
\hline \multicolumn{4}{|l|}{$\begin{array}{l}\text { 14a. Have you been treated/or sought treatment for an STD in the past } 12 \text { months? } \\
\text { (Umewahi kutibiwa au kutafuta matibabu ya ugonjwa wa zinaa kwa mda wa miezi } \\
\text { kumi na miwili iliyopita?) }\end{array}$} \\
\hline \multicolumn{4}{|c|}{$\begin{array}{l}\text { 15. Have you experienced ( Read from list below---------) the past } 12 \text { months before coming to the clinic today? } \\
\text { (Katika mwezi kumi na miwili iliyopita, umewahi ......) }\end{array}$} \\
\hline $\begin{array}{l}\text { Lower abdominal pain } \\
\text { (Kuwa na maumivu katika sehemu ya chini mwa tumbo lake) }\end{array}$ & & & \\
\hline & & & \\
\hline
\end{tabular}




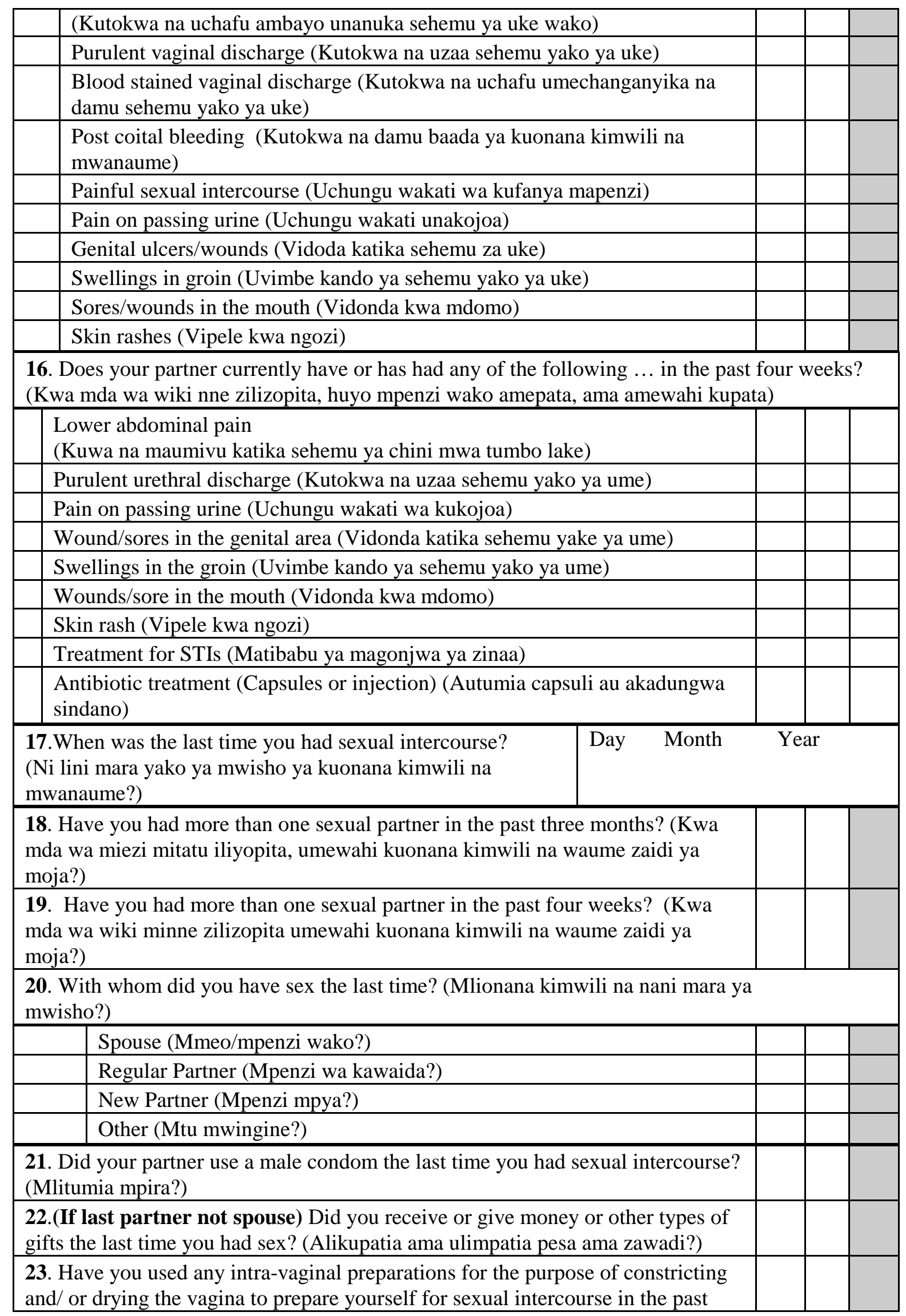


three months? (Katika miezi mitatu iliyopita, umewahi kutumia kitu chochote

cha kukausha ama kukaza sehema ya uke kabla kuonana kimwili na mwanaume?)

\section{Time consultation ended:}

